\title{
Polydimethylsiloxane Composites Characterization and Its Applications: A Review
}

\author{
Ronaldo Ariati ${ }^{1}$, Flaminio Sales ${ }^{1}$, Andrews Souza ${ }^{2}$, Rui A. Lima ${ }^{2,3, *}$ and João Ribeiro ${ }^{1,4}$ \\ 1 ESTiG, Instituto Politécnico de Bragança, 5300-252 Bragança, Portugal; a46685@alunos.ipb.pt (R.A.); \\ fcflaminio@gmail.com (F.S.); jribeiro@ipb.pt (J.R.) \\ 2 MEtRICs, Mechanical Engineering Department, Campus de Azurém, University of Minho, \\ 4800-058 Guimarães, Portugal; andrewsv81@gmail.com \\ 3 CEFT, Faculdade de Engenharia da Universidade do Porto (FEUP), Rua Roberto Frias, \\ 4200-465 Porto, Portugal \\ 4 CIMO, Instituto Politécnico de Bragança, 5300-252 Bragança, Portugal \\ * Correspondence: rl@dem.uminho.pt
}

Citation: Ariati, R.; Sales, F.; Souza, A.; Lima, R.A.; Ribeiro, J. Polydimethylsiloxane Composites Characterization and Its Applications: A Review. Polymers 2021, 13, 4258. https://doi.org/ 10.3390/polym13234258

Academic Editor: Aleksander Hejna

Received: 31 October 2021

Accepted: 2 December 2021

Published: 5 December 2021

Publisher's Note: MDPI stays neutral with regard to jurisdictional claims in published maps and institutional affiliations.

Copyright: (C) 2021 by the author. Licensee MDPI, Basel, Switzerland. This article is an open access article distributed under the terms and conditions of the Creative Commons Attribution (CC BY) license (http://creativecommons.org/licenses /by/4.0/).

\begin{abstract}
Polydimethylsiloxane (PDMS) is one of the most promising elastomers due its remarkable proprieties such as good thermal stability, biocompatibility, corrosion resistance, flexibility, low cost, ease of use, chemically inertia, hyperplastic characteristics, and gas permeability. Thus, it can be used in areas such as microfluidic systems, biomedical devices, electronic components, membranes for filtering and pervaporation, sensors, and coatings. Although pure PDMS has low mechanical properties, such as low modulus of elasticity and strength, it can be improved by mixing the PDMS with other polymers and by adding particles or reinforcements. Fiber-reinforced PDMS has proved to be a good alternative to manufacturing flexible displays, batteries, wearable devices, tactile sensors, and energy harvesting systems. PDMS and particulates are often used in the separation of liquids from wastewater by means of porosity followed by hydrophobicity. Waxes such as beeswax and paraffin have proved to be materials capable of improving properties such as the hydrophobic, corrosion-resistant, thermal, and optical properties of PDMS. Finally, when blended with polymers such as poly (vinyl chloride-co-vinyl acetate), PDMS becomes a highly efficient alternative for membrane separation applications. However, to the best of our knowledge there are few works dedicated to the review and comparison of different PDMS composites. Hence, this review will be focused on PDMS composites, their respective applications, and properties. Generally, the combination of elastomer with fibers, particles, waxes, polymers, and others it will be discussed, with the aim of producing a review that demonstrates the wide applications of this material and how tailored characteristics can be reached for custom applications.
\end{abstract}

Keywords: PDMS; PDMS composites; mechanical properties; optical properties; biocompatibility

\section{Introduction}

Polymers are a large class of materials that are widely used and the basis of several industrial goods [1]. They are formed by means of the chemical linking of smaller molecules (the monomers), and according to the number and characteristics of these bonded molecules, different properties can be achieved [2]. Natural polymers or biopolymers are those obtained from nature, for example, polysaccharides and proteins [3]. Synthetic or artificial polymers are produced in laboratories and are mostly derived from petroleum, e.g., acrylic, polyvinyl chloride (PVC), polyethylene, and polypropylene. Among the polymers are elastomers that have viscous and elastic characteristics. It is considered a viscous substance and has a dense, thick, and sticky consistency. Its applications are selected for materials that, when tension is applied, have the property of returning to their original shape, such as tires, rubbers, and elastics [4]. Polydimethylsiloxane, commonly known as 
PDMS, is a component belonging to the popularly known organosilicon group of silicones. PDMS is the most widely used silicone based on organic polymers that presents the characteristics of a transparent, flexible compound with biocompatibility properties [5]. As such, they are used in various applications and can be found in daily use in products such as synthetic fibers, plastic bags, paints, lenses, glues, and biomedical devices [611]. In addition, the polymeric industry has grown quickly and nowadays is one of the biggest industries [12].

An important subclass of polymeric materials is the elastomers. They are cross-linked polymers that have, in general, a low Young's modulus, high-yield strains, and the ability to restore the original shape when a stress ceases. Examples of elastomers include natural and synthetic rubbers, silicone elastomers, and other copolymers [13,14].

One of the most promising elastomers is the polydimethylsiloxane (PDMS). It is a highly used silicon-based polymer with good chemical and thermal stability [4,15-17], biocompatibility [18-20], corrosion resistance [21,22], flexibility [23-25], repeatability [26], a low cost [27], ease of use, chemically inertia, hyperplastic characteristics, and gas permeability $[3,28]$. Thus, PDMS has been used in several fields and systems (see Figure 1), such as microfluidics and nanofluidics [29-37], biomodels [38,39], organ-on-a-chip platforms [40,41], blood analogues [42-46], electronic components [47], membranes for filtering and pervaporation [48-50], sensors [51-53], optical and thermal devices [54-56], coatings [57-59], etc. However, several PDMS applications can be compromised due to its low mechanical properties, such as low elasticity modulus and strength. One way to overcome this limitation is by performing bulk modifications that create PDMS composites with tailored properties. These modifications can be achieved by inserting free molecules (nano or microparticles) and by changing the pre-polymer composition [25]. In addition, Mi et al. [43] have shown that the tensile properties of PDMS can be improved by adding silica fibers.
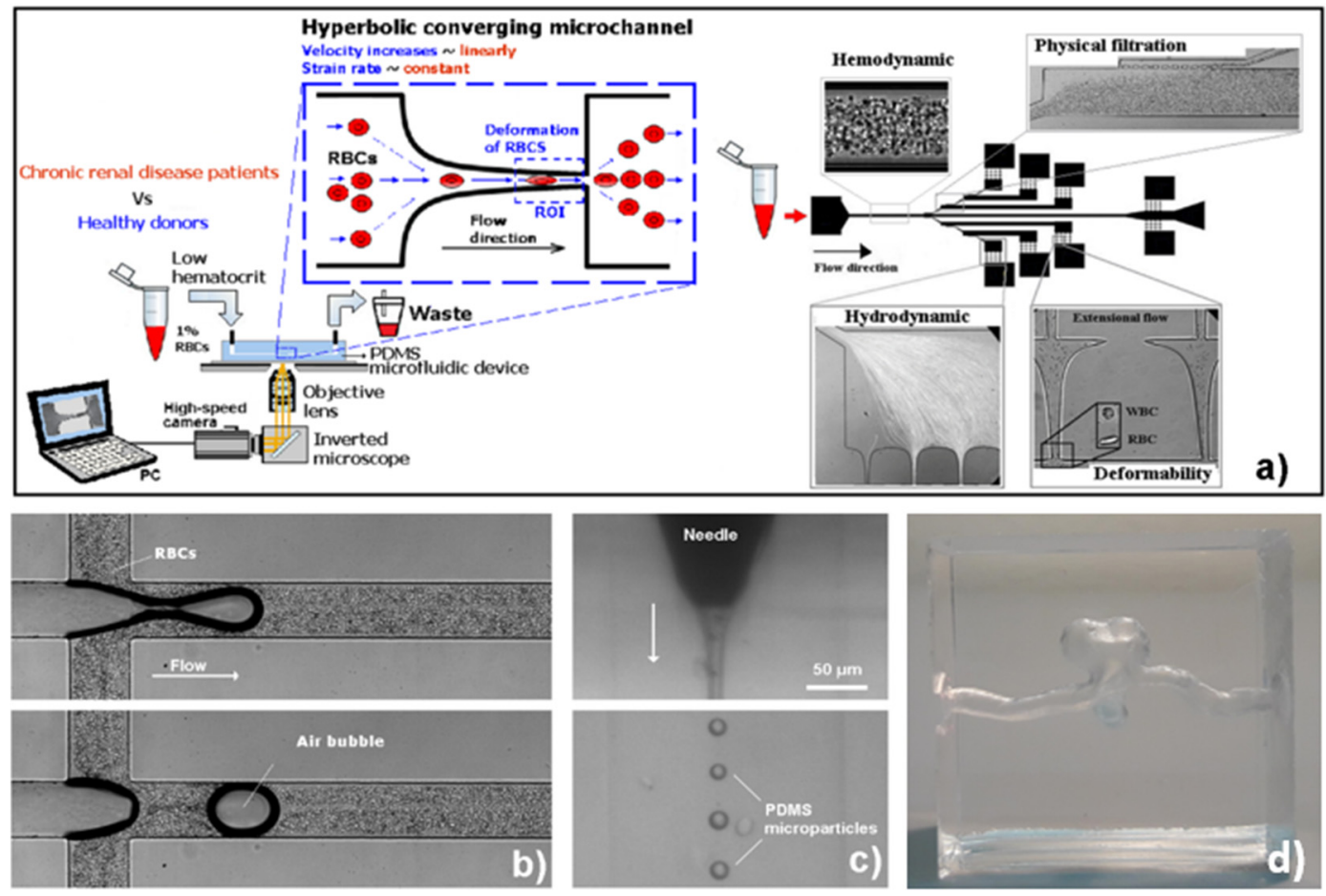

Figure 1. PDMS applications: (a) in microfluidic devices to assess motions and deformations of red blood cells (RBCs) from healthy donors and pathological patients [36]; (b) in microchannel networks to investigate gas embolism [38]; (c) with a flow-focusing technique to generate micro-sized PDMS particles [44]; (d) with PDMS biomodels to assess the blood flow behavior in aneurisms [39]. 
Despite the large number of papers that show the applications and properties of pure PDMS, there are few works dedicated to listing, reviewing, and comparing information about its composites. Hence, this review shows not only the PDMS composites' characterization and their applications but also the potential of this material. First, an overview of the research studies performed with PDMS composites was made, highlighting the works where the addition of other materials in PDMS has promoted significant changes in PDMS's properties. This review is focused on discussing the combination of PDMS with fibers, particles, waxes, and polymers, among others, and its potential applications.

\section{Polydimethylsiloxane}

PDMS is a polymer classified as a silicon elastomer, which means it is constituted by a combination of inorganic chains with high surface energy, associated with silicates, methyl groups, inorganics, and low surface energy. Inside PDMS's chemical structure, these methyl groups are prevalent and crucial to provide PDMS hydrophobic characteristics, with a surface tension around $20.4 \mathrm{mN} / \mathrm{m}$ [60].

The synthesis of PDMS typically begins with hydrolysis and the condensation reaction of dichlorosilanes, obtaining cyclic and linear polymers [61]. This synthesis methodology results in a weak control of molecular weight originating polymers with low properties, which cannot be used in most practical applications [62]. Hence, to improve the control of the molecular parameters, the previous synthesis method was progressively replaced by the ring-opening polymerization of cyclic siloxanes. It should be noted that the kinetically controlled polymerization of PDMS is based on the anionic polymerization of hexamethylcyclotrisiloxane monomer. This synthesis method allows the formulation of almost monodisperse PDMS with customized structures based on a chain reaction in which a specific catalyst reacts with hexamethylcyclotrisiloxane to generate short silanolate-ended chains that are able to attack other hexamethylcyclotrisiloxane molecules to produce the desired polymer [63].

The chemical structure consists of a $(\mathrm{Si}-\mathrm{O})$ backbone and repetitive $\left(\mathrm{Si}\left(\mathrm{CH}_{3}\right)_{2} \mathrm{O}\right)$ units that can be expressed as $\mathrm{CH}_{3}\left[\mathrm{Si}\left(\mathrm{CH}_{3}\right)_{2} \mathrm{O}_{n}{ }_{n} \mathrm{Si}\left(\mathrm{CH}_{3}\right)_{3}\right.$, whereas $n$ represents the number of repetitive units. These repetitions define materials' molecular weight, which consequently defines properties such as viscoelasticity. Furthermore, $\left(\mathrm{CH}_{3}\right)$ represents the methyl group, and $(\mathrm{Si}-\mathrm{O})$ represents the strength of the siloxane bonds that make this material chemically and thermally stable. The crosslinking reaction, with groups such as phenyl and vinyl, can carry out large property changes for different applications. Crosslinking reactions, with groups as phenyl and vinyl can accomplish great property changes for different applications $[25,64,65]$.

One of the main areas where this elastomer is used is in the biomedical field; thus, the material presents high biocompatibility and biostability. These terms are related to materials that do not cause adverse effects when they come into contact with biological tissues. Although the mechanism for biocompatibility is still not totally clearly demonstrated, it is known that interactions with water in proteins are fundamental parameters and are related to physicochemical characteristics such as surface free energy, stiffness, surface charge, and wettability [66].

Another important aspect of biomaterials refers to structural biocompatibility. This is related to the mechanical interactions between an implanted device and the surrounding tissues. The mismatch of mechanical properties can cause inflammation or incorrect support of the efforts present [67].

Regarding mechanical properties, pure PDMS usually shows an elastic modulus between 1.32 and $2.97 \mathrm{MPa}$ and tensile strength from 3.51 to $5.13 \mathrm{MPa}$. These values vary depending on the curing agent ratio and curing temperature during the manufacturing process. The tensile values rise with the increasing temperature until it reaches $125^{\circ} \mathrm{C}$; temperatures above this value reduce the tensile strength, but Young's modulus continues growing and presents a linear relation with the temperature. [68,69]. An increase in the curing agent ratio can lead a reduction in PDMS's flexibility and, consequently, reduces 
the Young's Modulus [70,71]. The hardness is usually proportional to the Young's modulus and presents values around 43 Shore A [72-74].

Besides being optically transparent, having a low cost and high capability to replicate models as well as its use in rapid prototyping, pure PDMS has limitations. For instance, high hydrophobicity can be a problem when filling microchannels, as it makes it necessary to resort to temporary surface treatment procedures, such as oxygen plasma. Other restraints occur due to the permeability of the material, which can interfere with cell cultures. The main disadvantage of PDMS is its structural application, which may be extremely specific and reduced. Furthermore, the modification of its characteristics, such as transparency, can be interesting for the use in sensors and some types of coatings $[25,67,75]$.

\section{PDMS Composites}

Despite the large deformation capacity of the pure elastomers, fillers or reinforcements are often used to create composites that usually exhibit increased stiffness modulus, fracture toughness, fatigue resistance, tensile strength, and abrasion resistance [76,77].

Thus, filler characteristics such as volumetric fraction, shape, size, and dispersion are extremely important [78].

Even more crucial for the final properties is the interaction between the elastomer and the filler, which increases the degree of crosslinking. This characteristic is optimized if there are reactive surface groups and the particles inserted are small, which is the reason why many of the reinforcements used in this type of composite are nano- or microfibers and particles (see Figure 2a-d). Additionally, some agents can help the dispersion and coupling of the fillers in the composite. Usually, they are bifunctional molecules that provide bridges at the polymer-filler interface. Examples are silicone coupling agents, mercaptopropyltrimethoxysilane, and (3-triethoxysilylpropyl) tetra sulfide [79,80].

Therefore, the combination of PDMS with other materials allows the optimization and expansion of its applications and has already been extensively explored. The next topics discuss some of the main composites of the PDMS matrix, dividing them into materials filled with fibers or particles, and materials in which there is a combination of waxes (Figure 2e), polymers (Figure 2f), or another additive.
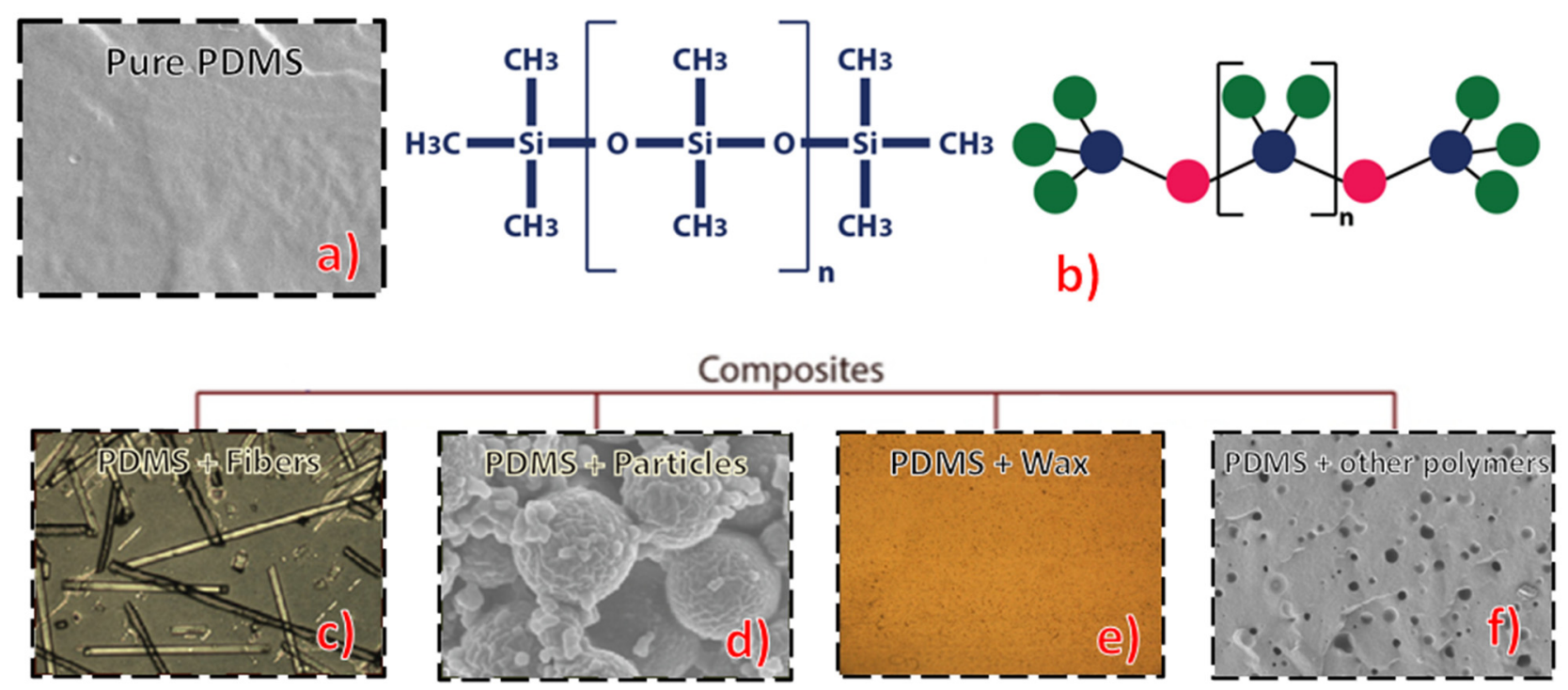

Figure 2. Pure PDMS and its compounds discussed in the present work: (a) Pure PDMS; (b) $\mathrm{CH}_{3}\left[\mathrm{Si}_{(}\left(\mathrm{CH}_{3}\right)_{2} \mathrm{O}_{3} n \mathrm{Si}_{(\mathrm{CH}}\right)_{3}$; Composites: (c) with fiberglass reinforcement, adapted image from [81], (d) with tantalum ethoxide-nanoparticles, adapted image from [82], (e) with beeswax (f) with other polymer combination polyethylene glycol (PEG), image adapted from [83]. 


\subsection{Fiber- and Nanofiber-Reinforced PDMS}

Fiber-reinforced composites are one of the most successful materials in engineering applications nowadays. Besides the fact that polymers such as epoxy or polyurethane usually comprise the matrix, the use of elastomer matrices is promising for applications such as a "muscle" actuator, flexible surfaces for aircraft aerodynamic components, and safer flywheels [84]. Additionally, for biomedical applications, carbon fillers inside a polymer can become an alternative to metallic devices, as they present advantages such as radiolucency and high mechanical properties. However, after cyclical sterilization, the interaction between phases can be compromised [85].

Likewise, fibrous fillers for PDMS are not widely studied in the literature. The distribution of reinforcements can be difficult, especially when using nanofibers, generating fillers' agglomeration and voids, which impairs and complicates their mechanical properties. However, studies in which electrospun polyacrylonitrile-graft-polydimethylsiloxane fibers were introduced as a graft copolymer on a PDMS matrix in non-woven and aligned portions reached satisfactory results, increasing the tensile strength from 0.3 MPa up to 2.3 MPa. Additionally, the Young Modulus, which was $47 \mathrm{MPa}$ for the pure silicone sample, increased to $119 \mathrm{MPa}$ when using non-woven fillers and $674 \mathrm{MPa}$ for aligned reinforcements [86]. Another work reached an increase in mechanical and thermal properties when using a PDMS and graphene foam matrix reinforced with carbon fiber. The increase in the tensile strength, Young's modulus, and thermal conductivity was $52 \%, 71 \%$, and $41 \%$, respectively, when comparing it with the pure matrix [87].

A combination of PDMS with carbon fillers has already been proposed as an alternative for the fabrication of flexible displays, batteries, wearable devices, and tactile sensors used for robotics [49,50]. By combining short carbon fiber with elastomer in a method known as spatial confining forced network assembly, an electrical conductivity around $1.67 \times 10^{2} \mathrm{~S} / \mathrm{m}$ was obtained, which is superior to that presented by pure PDMS, an insulator with conductivity in the order of $10^{-12} \mathrm{~S} / \mathrm{m}$. Additionally, when pre-compressed, this composite can reach even higher conductivity, around $3.2 \times 10^{2} \mathrm{~S} / \mathrm{m}[88]$.

When using dual-scale carbon fillers, a combination of carbon nanofibers and short carbon fibers, the disparity between the elastic modulus of the elastomeric matrix and the conductive graft, used as a sensor, was reduced. This leads to the increased sensitivity, stretchability, and repeatability of high-strain sensors, reaching small drifts in resistance even after 300 loading cycles [89]. A related application can be found in the manufacturing of harvesting energy devices. These are normally constituted by piezoelectric ceramic and present problems such as the possibility of failures when submitted to cyclical efforts, due to the fragility of the ceramic, and environmental impact, as they usually contain lead, which is classified as a substance of very high concern. $\mathrm{K}_{0.485} \mathrm{Na}_{0.485} \mathrm{Li}_{0.03} \mathrm{NbO}_{3}(\mathrm{KNLN})$ fibers in PDMS have achieved a piezoelectric charge and voltage comparable to that of ceramic PZTs in a mechanically compliant and environmentally friendly material [90]. Satisfactory results for energy harvesting and piezoelectric uses were also assessed using the elastomeric matrix and $\mathrm{BaTiO}_{3}$ nanofibers, another lead-free alternative that can be aligned in the matrix and reached output voltage values between 0.56 and $2.67 \mathrm{~V}$ when a periodic mechanical compression with a pressure of $2 \mathrm{~Pa}$ was applied [91]. Additionally, when using silver microfibers in a soft litography process, the conductivity of the PDMS increased, changing the resistance from $0.12 \Omega \mathrm{m}$ (for $10 \% \mathrm{wt}$ ) to $0.000001 \Omega \mathrm{m}$; using $8 \% \mathrm{wt}$ of short carbon fiber fillers, the resistance of a 0.1-millimeter-thick sample was 0.0026 and could reach values three times lower with the insertion $1 \%$ wt of a second conductive nanofiller $[92,93]$.

Reinforcements can also allow the use of PDMS in high-performance composites, maintaining good transparency. Studies using just 1\%wt of three-dimensional silica continuous fiber reinforcements were achieved, in comparison with the pure matrix, which showed increases of $140 \%, 94 \%, 18 \%$, and $95 \%$ in tensile modulus, strength, maximum strain, and tear strength, respectively [81]. The optical properties of the elastomer can also be explored to analyze fiber alignment in processes such as injection molding, where a 
study was able to visualize the flow during the injection and determine how carbon fiber inserts' positioning could be improved [94]. Furthermore, the use of PDMS as an NCF fiber-optic interferometer coating showed excellent thermal performance, resulting in a significant improvement in temperature sensitivity when compared to a pure silica fiber interferometer. PDMS was used as fiber coating to improve the fragility of the fiber structure, thus increasing its reliability for practical applications [53]. Likewise, tailored properties can be achieved to match living tissue requirements, such as a bone elasticity modulus. This way, the combination of 55 vol.\% of aramid balanced fabric reinforcement, PDMS, and 0-25\% vol.\% nano/micro hydroxyapatite and tricalcium phosphate reached a modulus of elasticity, in bending, similar to that presented by human cortical bones (14$20 \mathrm{GPa}$ ), which is suitable for bone surgeries [95]. For stretchable electronics, a PDMS/plain weft-knitted nylon fabric showed a huge increase in fracture toughness of about $700 \%$, which is much higher than that of pure PDMS, and maintaining high elasticity (Young's modulus around $2 \mathrm{MPa}$ ). Additionally, during cyclic loading, for small stretches, the behavior was linear elastic, and, for a relatively large stretch, it had significant hysteresis [96].

\subsection{Addition of Particles to PDMS}

Particles are one of the most common additions in PDMS. When one of the dimensions of the inserted fillers is smaller than $100 \mathrm{~nm}$, the formation of nanocomposites occurs. Another common occurrence is micro composites, with particles on the micrometric scale. Examples of particles include carbon nanotubes, some silicates, and graphene [25].

Porous compounds using PDMS and particulates are commonly used to improve absorption efficiency in the separation of liquids from wastewater due to their porosity and super hydrophobicity. PDMS shows benefits for the reusable compound, as it can be pressed repeatedly without structure loss. Additionally, as a low-cost material, it can reduce the cost of effluent treatment, as these processes generally require a large number of absorbent materials. Nanoparticles are used to improve surface roughness, which leads to an increase in super hydrophobicity, reaching a contact angle with water greater than $150^{\circ}$ and allowing the droplets to slide under the surface. PDMS acts as a strong binding and immunization adhesive for nanoparticles, and one of the main advantages of this application is its non-toxicity. Some works manufactured porous compounds modified with $\mathrm{SiO}_{2}$ nanoparticles and others used $\mathrm{TiO}_{2}$ nanoparticles as modification agents, coated with PDMS and manufactured by a simple immersion technique. Melanin sponges have high efficiency in removing oil from water through micro- and nanoparticles of tungsten disulfide $\left(\mathrm{WS}_{2}\right)$ and $\mathrm{SiO}_{2}$, respectively. The particles are immobilized on the sponge surface by a layer of polydimethylsiloxane adhesive that features an extremely water-repellent structure by a simple one-step immersion process. The composite sponge has high oil absorption at 21e112 times its own weight and a selectivity efficiency above $99.8 \%$, as shown in Figure 3 [97]. Likewise, using silicon nanoparticles as a coating substrate was produced by simple immersion followed by magnetic stirring in order to reduce the surface drag force. The drag force reduction rate decreased by $24 \%$, and the coating showed greater durability in acidic and alkaline solutions [98]. $\mathrm{TiO}_{2}$ additives are also applied to create electroactive material based on PDMS; this material shows reduced drive voltage and response speed in comparison with a traditional silicone-poly(hexylthiophene) electroactive polymer [99].

Metallic meshes with different pore sizes were coated with nanoparticles and nanocomposites by an immersion process. Hydrophobic titanium diode was used as a nanoparticle and polydimethylsiloxane as a binding resin. The presence of PDMS resulted in an improvement in the mechanical durability of wire mesh. Besides that, it was found that meshes with smaller pores are more efficient in separation; however, the process takes longer [100]. Likewise, a porous sponge with photocatalytic properties, manufactured with PDMS and $\mathrm{TiO}_{2}$, was used for the degradation and demolition of organic pollutants in textile wastewater. These nanoparticles were injected into the polydimethylsiloxane 
sponge, were able to demote up to $50 \%$ of the pollutants without the presence of light and $80 \%$ with light; this is due to degradation of the photocatalytic action of $\mathrm{TiO}_{2}$, allowing greater absorption of the dye from the solution [101]. Furthermore, $\mathrm{TiO}_{2}$ nanoparticles were added to the PDMS matrix by a spin-coating method and used as coatings on metals to improve the corrosive capacity of the material. Corrosion resistance improved with the $8 \%$ by weight proportion of $\mathrm{TiO}_{2}$, which achieved the best performance [102].
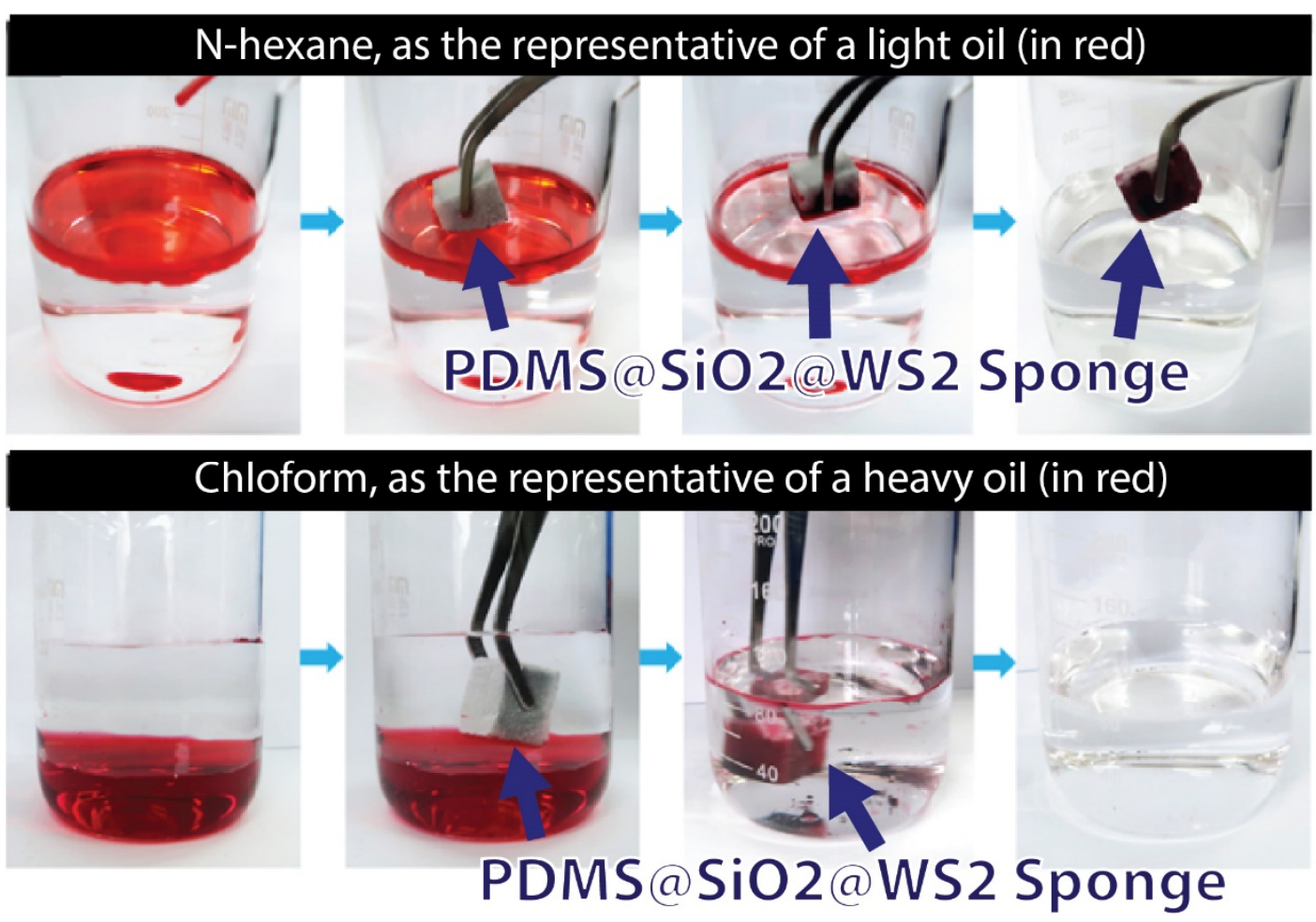

Figure 3. $\mathrm{PDMS} / \mathrm{SiO}_{2} / \mathrm{WS}_{2}$ sponge for application in oil separation, adapted from [97].

In addition, metallic particles in PDMS films or substrates have been studied for various applications. For example, micro-pumps can be created, taking advantage of the elasticity and mobility of PDMS membranes and using magnetic actuators to generate deflections by attracting iron particles [103]. The same composite with magnetic properties could find application in the control of droplet motion, a useful resource in the manipulation of sample drops in chemical and biological tests and studies [104]. When comparing different magnetic fillers, pristine carbonyl iron microparticles (CI) reached a maximum deflection of $762 \mu \mathrm{m}$ at $0.27 \mathrm{mT}$ for a membrane diameter of $6.2 \mathrm{~mm}$, which was the highest result in a study that also evaluated lauric acid-coated superparamagnetic iron-oxide nanoparticles (SPION-LA) and lauric acid-coated carbonyl iron microparticles (CI-LA) [105].

The porosity and water absorption of the PDMS cell scaffolds are inversely proportional to particle size. However, the interconnectivity of PDMS cell scaffolds increases with increasing particle dimension. Additionally, mechanical properties such as compressive modulus and compressive strength obtained higher values for intermediate pore sizes, between 300-450 $\mu \mathrm{m}$, in a sample universe with 150-300, 300-450, and 450-600 $\mu \mathrm{m}$ pores [106].

\subsection{Wax Addition}

Waxes such as beeswax and paraffin proved to be materials capable of improving the hydrophobicity corrosion resistance and the thermal and optical properties of PDMS, leading to applications such as wearable devices, sensors, and superhydrophobic coating [75]. 
A phase change functional compound consisting of PDMS such as matrix and paraffin was prepared by the molten mixture method and has demonstrated excellent performance in thermal and mechanical properties. The compound has excellent flexibility and heat absorption capacity. As the paraffin content increases, the temperature sensitivity of the mechanical property also increases, and the composite's storage modulus decreases with increasing temperature. Consequently, substrate thermal management flexibility is enhanced with increasing temperature, thus applying to a flexible substrate. The change in the transmittance of composites due to the phase change of the paraffin makes it applicable as a visual warning of temperature increase [107]. Additionally, with the addition of paraffin spheres in the PDMS matrix, the composite had an increase of more than an order of magnitude in stiffness in a compression test [108]. Another work aimed to improve the transparency of the compound with a percentage of up to $10 \% \mathrm{wt}$ of paraffin without changing the transparency of the film. During optical testing, the compound was determined not to be ideal for use as a transparent reflective key, but there have since been considerable additional improvements [109].

Another interesting coating using PDMS combined with paraffin wax is found in the textile engineering field, where it is manufactured using a simple inlaying process. The prepared textiles exhibited stability after mechanical abrasion and chemical corrosion. Furthermore, the coated textiles have excellent self-cleaning and water repellence abilities and can be used to separate various types of liquid mixtures such as oil-water, diesel oil, and crude oil. The separation efficiency can reach up to $95 \%$ in the separation of the diesel oil-water mixture specifically [110]. A new method of modifying the surface properties of filter papers, making them super hydrophilic and super oleophobic underwater in a simple and economical way, was presented in Figure 4. Both super hydrophilic and super oleophobic paper can reach up to $99 \%$ efficiency for gravity oil-water separation [111].

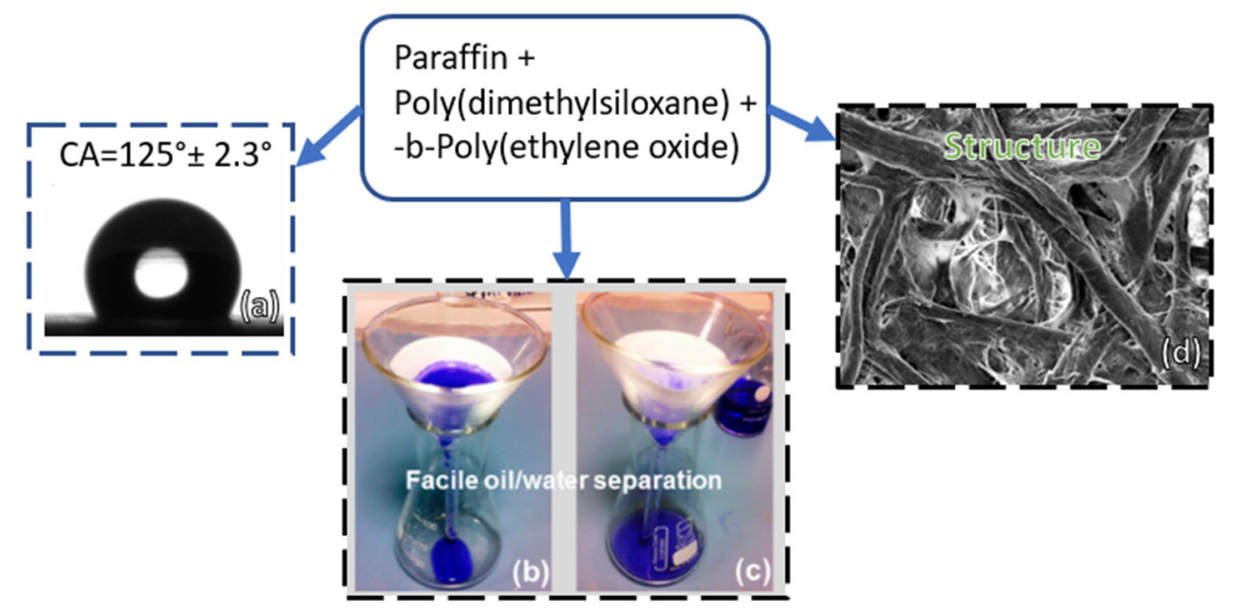

Figure 4. Oil-water separation by filter paper, oil remains on the filter paper while water with blue dye passes through the filter paper, adapted from [111]: (a) Contact angle, (b,c) oil/water separation and (d) structure of filter paper.

Other transparent and flexible composite films with a selectable mist using a lamination process have been manufactured. The film is composed of polyethylene terephthalate, graphene, and paraffin organogel-PDMS substrates. When graphene is heated, a transformation occurs in the paraffin impregnated in the PDMS, leading to an improvement in light scattering. Transmittance is maintained above $90 \%$ in the visible range, while fog can be controlled in the range from 0.5 to $85 \%$ by applying a voltage of $18 \mathrm{~V}$ with a consumption of $0.33 \mathrm{~W} / \mathrm{cm}^{2}$. Optical film that enables transmittance control can be used to enhance the light-capturing properties of photovoltaic panels and windows, allowing for privacy [112]. Another method consists of applying a voltage of $10 \mathrm{~V}$ on the composite 
film, which then undergoes a rapid change from opaque to transparent in less than $8 \mathrm{~s}$ followed by transmittance, which changes from $2 \%$ to $75 \%$ [113].

However, it is also possible to have adhesive films with the same function of switching between opaqueness and transparency via a thermal trigger. The appearance of the film alternates between opaque at room temperature and clear at temperatures above 53 ${ }^{\circ} \mathrm{C}$. The change in optical properties is almost instantaneous, and the application is best suited for use as a low-cost, smart window coating [114].

In order to meet the needs of protection against oxidative substances, corrosive liquids and ultraviolet light that limit the practical application of solar vapor generation were employed. Photothermal conversion coatings were manufactured with stable chemical and mechanical properties by a spray process with a mixture of beeswax, multiwalled carbon nanotubes, and polydimethylsiloxane. The coatings exhibited good broadband light absorption capacity efficiently under sunlight irradiation. The superhydrophobicity caused by beeswax and PDMS provides self-cleaning that can prevent the reduction in steam generation efficiency induced by microorganisms and mud in the water and are able to heal damage to superhydrophobicity through the migration of beeswax, providing lasting protection. Due to their low maintenance requirements, simple preparation process and high cost effectiveness, photothermal conversion coatings are suitable for supplying fresh water to remote or disastrous areas [115].

Another work used natural carnauba wax and PDMS to fabricate superhydrophobic surfaces using model transfer and colloidal deposition method, which consists of depositing carnauba wax on the surface. The secret to the superhydrophobic surface was rubbing to remove the weakly connected wax particles. After removing the loosely bound particles, the surface becomes super-hydrophobic with a contact angle greater than $150^{\circ}$ and a slip angle less than $10^{\circ}$. The surface has good mechanical durability against abrasion and water impact. As they are biocompatible materials and possess these characteristics, they have become widely used in biomedical applications due to their repellency to blood and its components, presenting reduced drag to the blood and a coagulation time of at least one hour [116]. This makes it ideal for manufacturing blood-compatible materials and microfluid devices used in blood separation and typing as well as its application to self-cleaning surgical garments. The super hydrophobic surface containing carnauba wax and PDMS has good mechanical durability against abrasion and water impact and is therefore suitable for outdoor environments [117].

Another application of PDMS combined with paraffin wax is used in a new hermetic encapsulation method for microfluidic devices actuated by negative pressure. The airtight materials used are non-active, non-hazardous, and commonly used as sealing materials for plastic medicine and food packaging. The new method offers advantages such as the ability to steer for more than 3 weeks without any vacuum equipment and only allowing air intake when the device is encapsulated [118].

\subsection{Blends with Other Polymers}

The search for ecological materials for membrane separation is becoming highly attractive and increasingly competitive, always focusing on the low cost and high separation efficiency that are present in the main industrial processes. New gas separation membranes using a copolymer of poly (vinyl chloride-co-vinylacetate) (PVCA) and polydimethylsiloxane (PDMS) were manufactured using a simple method of mixing followed by constant agitation. The separation performance was carried out by permeation studies on pure phases $\mathrm{CO}_{2}, \mathrm{~N}_{2}$, and $\mathrm{CH}_{4}$ at different temperatures. After characterization tests, the membranes showed better selectivity and high flux at $25^{\circ} \mathrm{C}$, and as the temperature increased up to $75^{\circ} \mathrm{C}$, the selectivity and flux decreased. It was found that with the addition of PVCA to PDMS, the mechanical and thermal stability improved by more than $25 \%$ and $6 \%$, respectively. The results were positive with the combination of PVCA and PDMS, in which lead to the development of a homogeneous dense film structure [119]. Likewise, PDMS-graft copolyimides were synthesized through polycondensation followed by 
chemical imidization to investigate the effects of the PDMS segment, and then the copolymide membranes were prepared by the solvent-casting method. The gas permeability coefficients of the copolymer membranes increased with the increase in the length of the PDMS segment, but they decreased after heat treatment at $200^{\circ} \mathrm{C}$. In addition, high gas permeability caused by the continuous phase of the PDMS flexible domain, along with improved pervaporation when it requires efficient removal of VOCs from aqueous mixtures, was verified. PDMS-grafted copolymer membranes showed efficiency in removing toxic organic components from wastewater due to an improved pervaporation technique [120]. Additionally, another pervaporation membrane composed of $\mathrm{SiO}_{2} / \mathrm{PDMS} / \mathrm{PVDF}$ was manufactured by the dynamic negative pressure method and showed a significant improvement of more than $40 \%$ in the contact angle with the surface compared to the PVDF membrane alone. The permeation of phenol into water also increased. $\mathrm{The}^{\mathrm{SiO}_{2}}$ dispersed in the PDMS solution improved mechanical strength and phenol recovery, which strongly suggests the removal of phenols in wastewater from coal gasification [121].

With the aim of making the pervaporation process more efficient and producing it on a large scale, a non-porous PDMS composite membrane with surface standardization in two stages was manufactured. First, the PVDF substrate was patterned in two layers using phase separation micro-molding followed by modifying dipping precipitation, and then, the PDMS solution was prepared with different types of crosslinking agents that were cast onto the patterned substrate prepared as a selective layer. The permeation of the standardized membrane with the crosslinking agent TEOS showed a larger pattern size, generally more than 2 times higher than the non-standardized one, while with VTES and p-TTES, they improved the polymer stiffness; thus, it is an effective way to improve the pervaporation flow. Micropatterned PDMS composite membranes show great potential in large-scale industrial application for bioethanol recovery [59].

In the investigation of solutions to ice accumulation on surfaces, superhydrophobic coatings using crosslinked PHC microspheres that have been combined with adhesive PDMS by a single-step precipitation polymerization process have been presented. The coated surface showed a high contact angle and good mechanical durability due to micro/nanoscale structure, as well as self-cleaning and excellent water and ice repellent properties at low temperatures. Its applications are promising and efficient for anti-freeze coatings on external structures, as shown Figure 5 [122].

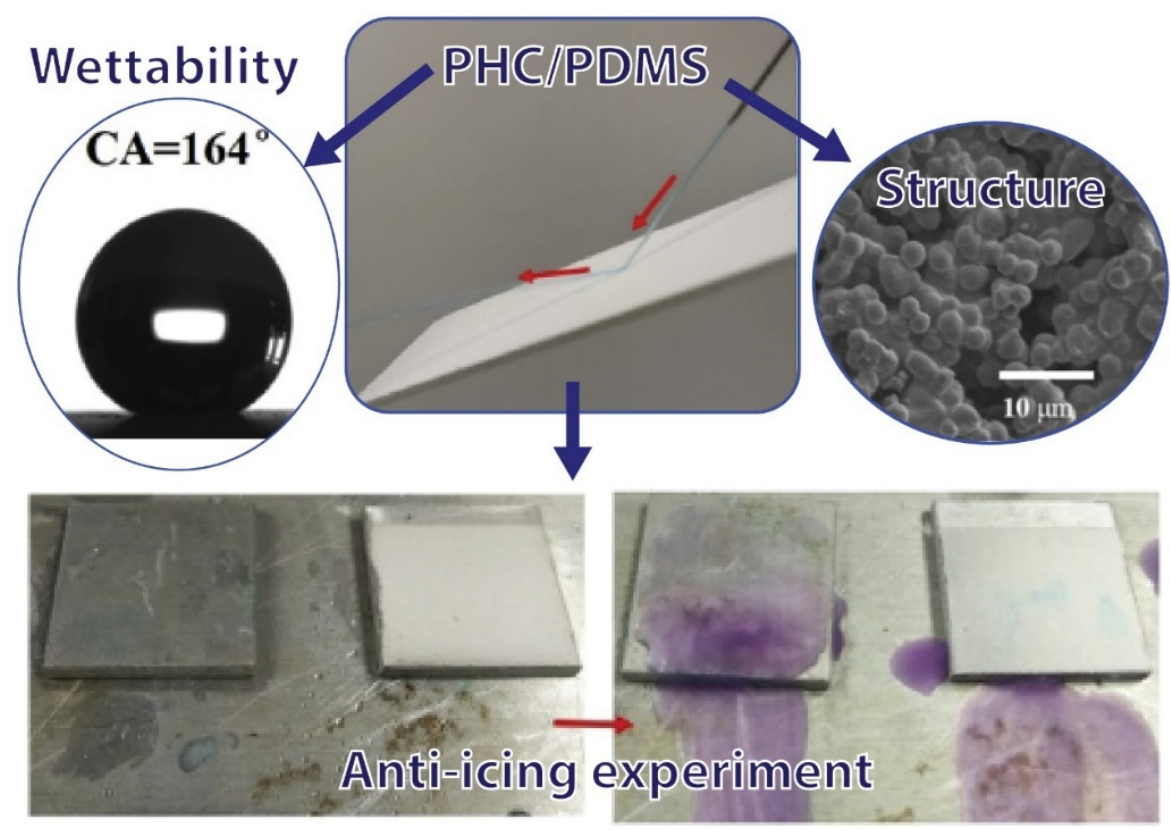

Figure 5. Using PHC/PDMS blends for anti-ice application, adapted from [122]. 
In several fields of application in biomedicine, PDMS stands as a biocompatible, nontoxic, and transparent material with good thermal and mechanical properties, considering the low cost of manufacturing and raw material. Elastomer PSUs were prepared from amino propyl-terminated PDMS, H12MDI, and APTMDS by a two-step polyaddition route. The PSU films showed high transparency, above $90 \%$, in the visible region, and a low elastic modulus, and the hysteresis values decreased from 32 to $2 \%$ in the tenth cycle, and the soft segment refractive index was increased through the incorporation of $14 \mathrm{~mol} \%$ of methyl-phenyl-siloxane. These results reveal that it is possible to use PSU films to replace the natural human lens after cataract surgery [123].

\subsection{Other Additions}

Another option is emerging in transforming surfaces of different types of substrates into super hydrophobic surfaces using the phase separation method. PDMS is used as a binder, tetrahydrofuran (THF) as a solvent, and water as a non-solvent. The modified fabric showed good self-cleaning ability, antifouling, and an excellent super-hydrophobic property, with a contact angle above $150^{\circ}$ and a slip angle below $10^{\circ}$, which are ideal conditions for oil-water separation devices. The advantages of this method are that there is no addition of nanoparticles, thus leaving no marks and no change in tissue color. The easy synthesis method has wide application potential for the fabrication of super hydrophobic surfaces [124].

Polyethylene glycol-blended polydimethylsiloxane elastomeric films were manufactured by a simple mixing process followed by mechanical agitation. The elastomeric films showed an increase in the degree of swelling as the amount of PEG increased, and the young modulus decreased with an increase in the amount of PEG. Although the effect of PEG on PDMS crosslinking deteriorates the mechanical properties of the material, it can be considered positive in terms of increasing hydrophilicity [83].

Flexible tactile sensors based on three-dimensional (3D) porous conductive composites were designed with a homogeneous synergistic conductive network of carbon black (CB) and carbon nanotube (MWCNTs) single-dip coating on a polydimethylsiloxane (PDMS) sponge skeleton, as shown Figure 6. The 3D porous structure with hybrid conductive networks of $\mathrm{CB} / \mathrm{MWCNTs}$ exhibited superior elasticity and excellent electrical characterization under external compression. This piezoresistive tactile sensor exhibited high sensitivity $\left(15 \mathrm{kPa}^{-1}\right)$, fast response time $(100 \mathrm{~ms})$, and the ability to detect small and large compressive deformations, as well as mechanical deformability and stability over 1000 cycles. The piezoresistive sensor has been used successfully in monitoring human physiological signals including finger heart rate, pulses, knee flexion, breathing, and finger gripping movements. The highly sensitive piezo-resistive sensor indicates great potential for applications in robotic-assisted surgery systems, human-machine interfaces, and low-cost wearable health electronics [125].

Membranes composed of polydimethylsiloxane combined with other additives have been studied in the most diverse everyday applications. The PDMS-D2HPA compound forms a gel layer on the outer surface of PVDF ultrafiltration hollow fibers through the application of a gallification technique to a new gel extraction membrane (EGM). Optimal extraction efficiency and EGM stability were achieved. The composite membrane showed more improvement in long-term operational stability than EGM flux attenuation, which was only $34 \%$ after $120 \mathrm{~h}$, whereas the conventional SLM was $100 \%$ after $45 \mathrm{~h}$. The advantages are evident, as EGM shows greater flow and operational stability than the conventional SLM process [126]. However, unlike the electrospinned PVDF layer in PDMScoated membranes, the electrospinned PDMS/PMMA or PDMS/PMMA/TPU membranes can be applied directly in the separation of wastewater from saline phenol with a better mass transfer coefficient [15].

Another work related to the selection of liquids consists of a porous hydrophobic sponge made of polydimethylsiloxane incorporating a small amount of graphene on the PDMS sponge skeleton surface through a process of mold surface transfer incorporation. 
The graphene-embedded PDMS sponge showed improved elasticity and durability and required less time to absorb the same amount of oil. However, robust and elastic mechanical sponges can be produced for direct application in oil-water separation in an underwater environment with less absorption time [127].

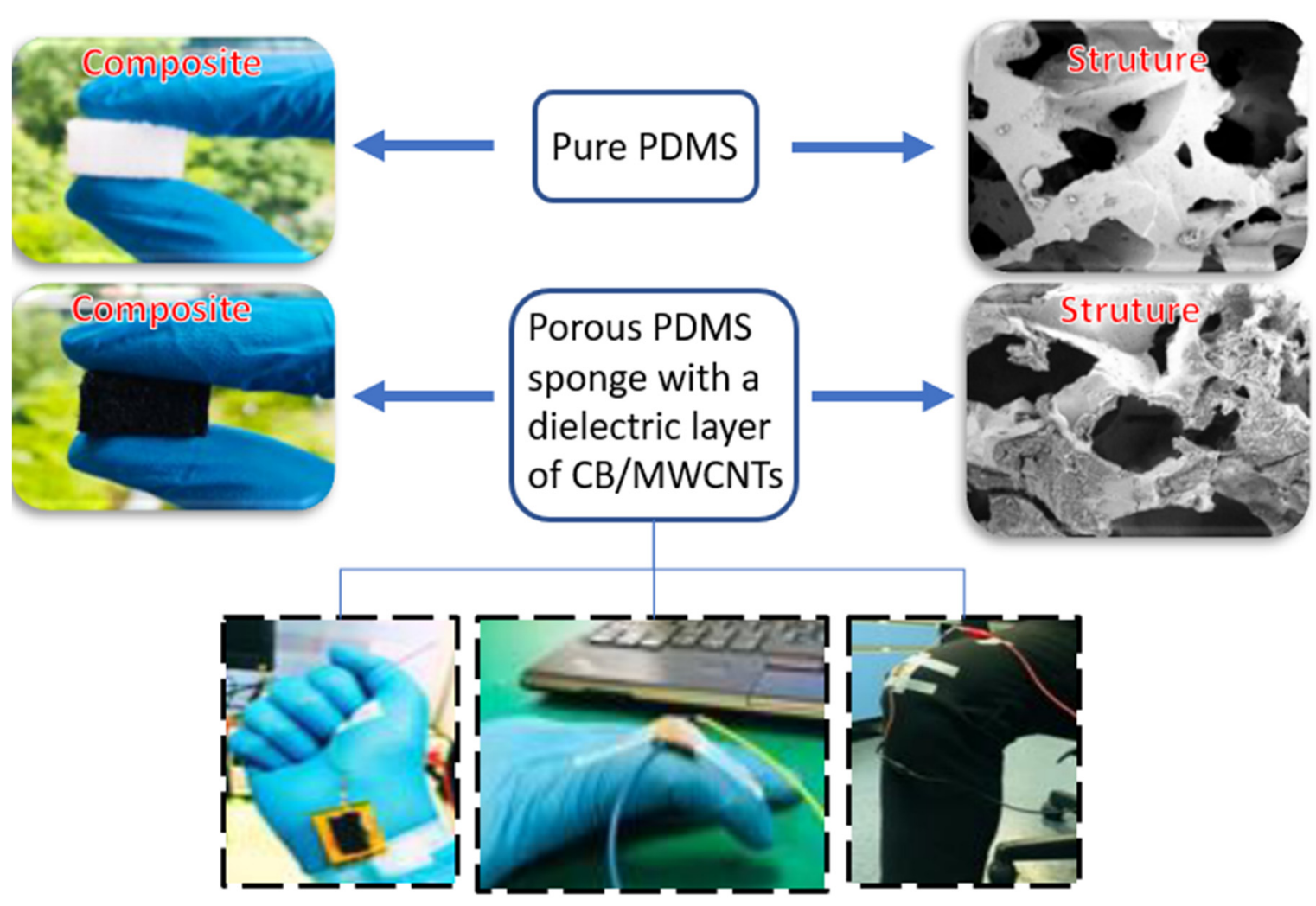

Figure 6. 3D porous sponge made of PDMS, carbon black and carbon nanotube for application in monitoring physiological signals, breathing, gripping movements, and heart rate, adapted from [125].

With the strong demand for superhydrophobic and self-cleaning surfaces, coatings containing PDMS and APTES were manufactured by a simple immersion process followed by room temperature curing. The coatings exhibited high contact angle and high transparency in the visible region, followed by excellent self-cleaning properties indoors and outdoors. In addition, the hybrid coating exhibited excellent antifogging behavior after prolonged exposure to mist and also presented good drop impact durability when applied outdoors [128]. In order to improve surfaces for superhydrophobic and self-cleaning properties, the PDMS-modified PU/Al coating with a smooth surface was prepared using PDMS-modified $\mathrm{PU}$ and $\mathrm{Al}$ powder flakes as a resin matrix and functional pigment. However, when the PDMS-modified PU/Al coating was modified by nano-SiOz, it presented a distinct micro-nano mastoid structure that was formed on the surface, allowing it to reach a contact angle above $150^{\circ}$ and a slip angle of less than $10^{\circ}$, thus achieving excellent selfcleaning performance and super-hydrophobicity [129].

Crosslinked membranes were fabricated by introducing LCs into a PDMS matrix using the preferred crosslinking method. The crosslinked membranes produced showed increased mechanical properties compared to pure PDMS membranes. PDMS/LC membranes also showed better membrane formation capacity, a lower hemolysis rate, lower platelet adhesion, and more favorable anticoagulant properties. Furthermore, the mechanical properties and blood compatibility of the membrane may be increased due to the introduction of cholesteric liquid crystals [19].

Surfaces with charge density, roughness, and morphology have a strong influence on the interaction of biomaterials and cells. A hybrid coating with hierarchical surface 
structures consisting of PDMS and tantalum oxide was fabricated using a simple one-pot, sol-gel-based method. The hybrid coatings showed structures with a combination of micron/submicron and nanoscale characteristics. Structures can be tailored from porous multilayer to single-layer films, depending on the concentration of tantalum oxide. The coatings showed good fibroblast adhesion and cell proliferation in a demonstration of their ability to modulate cell functions. This study demonstrated the coatings' potential application in the biomedical field to modulate cellular responses and improve implant performance [82].

Another field of application for PDMS is in a multifunctional dressing material, introducing a series of reduced graphene oxide ( $\mathrm{rGO}$ ) sheet contents into the PDMS matrix. The porous membrane was fabricated using the solvent evaporation-induced phase separation technique. The high porosity of the rGO-PDMS membrane on the lower surface is beneficial for cell adhesion and proliferation, and the small pores on the upper surface can prevent excessive water loss in wounds. The addition of rGO blades to PDMS improved mechanical strength, and it can be applied to dressings under high tension. The rGOPDMS composite membrane showed an increase of $35.33 \%$ in mechanical strength and $34.38 \%$ in elastic modulus. The membranes also showed the inhibition of bacterial growth and remarkably accelerated wound healing through increased re-epithelialization and the formation of granulation tissue. Therefore, it is a promising material that can be considered a multifunctional dressing [10].

\section{Results Summary}

Table 1 describes the main applications of PDMS mixed with other different types of materials, allowing for the direct and indirect analysis and comparison of some properties, such as tensile strength (TS), ultimate tensile strength (UTS), water contact angle (WCA) and sliding angle (SA). However, there is a summary of what was written in the body of the article discussing some mechanical, optical, and wettability properties.

Table 1. Summary of mechanical, optical, and wettability properties of PDMS combined with other materials.

\begin{tabular}{|c|c|c|c|c|c|}
\hline Type & Description & Reinforcement & Property & Value/Change & References \\
\hline Additive & Membrane & PDMS-PEG1 & $\begin{array}{c}\text { Young's modulus } \\
\text { TS }\end{array}$ & $\begin{array}{c}\text { Decreased } 22.0 \% \text { De- } \\
\text { creased } 6.0 \%\end{array}$ & [83] \\
\hline Additive & Sponge & Graphene/PDMS & WCA & $128.9 \pm 2.3^{\circ}$ & [127] \\
\hline Additive & Membrane & PDMS-D2EHPA & WCA & $102.0 \pm 2.0^{\circ}$ & [126] \\
\hline Additive & Sponge & THF as the solvent & WCA & $155.0 \pm 0.6^{\circ}$ & [124] \\
\hline Additive & Membrane & PDMS/PMMA & $\begin{array}{c}\text { TS at break } \\
\text { Elongation at break }\end{array}$ & $\begin{array}{c}1.7 \mathrm{MPa} \\
60.0 \%\end{array}$ & [15] \\
\hline Additive & Membrane & rGO-PDMS & $\begin{array}{c}\text { TS } \\
\text { Young's Modulus } \\
\text { Strain at break }\end{array}$ & $\begin{array}{c}\text { Increased } 35.33 \% \\
\text { Increased } 34.38 \% \\
\text { Increased } 7.0 \%\end{array}$ & [10] \\
\hline Additive & Membrane & PDMS/LC & $\begin{array}{l}\text { Stress at break } \\
\text { Elastic modulus }\end{array}$ & $\begin{array}{c}\text { Increased } 78.0 \% \\
4.7 \mathrm{MPa}\end{array}$ & [19] \\
\hline Additive & Coating & PDMS/APTES & $\begin{array}{c}\text { WCA } \\
\text { Transparency }\end{array}$ & $\begin{array}{l}103.9^{\circ} \\
91.2 \%\end{array}$ & [128] \\
\hline Blend & Membrane & PDMS/PVCA & $\begin{array}{c}\text { UTS } \\
\text { Elastic modulus } \\
\text { WCA }\end{array}$ & $\begin{array}{c}133.7 \mathrm{MPa} \\
2400 \mathrm{MPa} \\
99.2^{\circ}\end{array}$ & [119] \\
\hline Blend & Membrane & PIS6 & $\begin{array}{c}\text { Young's Modulus } \\
\text { TS } \\
\text { Elongation at break }\end{array}$ & $\begin{array}{c}400 \mathrm{MPa} \\
20 \mathrm{MPa} \\
100 \%\end{array}$ & [120] \\
\hline Blend & Characterization & PSU-3T & $\begin{array}{l}\text { Young's Modulus } \\
\text { UTS } \\
\text { Elongation at break }\end{array}$ & $\begin{array}{c}5.5 \mathrm{MPa} \\
6.0 \mathrm{MPa} \\
880 \%\end{array}$ & [130] \\
\hline Nanocomposite & Coating & PDMS/TEOS & $\begin{array}{l}\text { WCA } \\
\text { WVP }\end{array}$ & $130.0^{\circ}$ & [131] \\
\hline
\end{tabular}




\begin{tabular}{|c|c|c|c|c|c|}
\hline & & & & $7.9 \times 10^{-8} \frac{\mathrm{g}}{\mathrm{msPa}}$ & \\
\hline Nanocomposite & Films & PDMS-clay & Elastic Modulus & $1.5 \mathrm{MPa}$ & [132] \\
\hline Nanoparticle & Coating & $\begin{array}{l}\text { Tantalum oxide } \\
\text { /PDMS }\end{array}$ & WCA & $110.0^{\circ}$ & {$[82]$} \\
\hline Nanoparticle & Coating & PDMS/PU-Al and $\mathrm{SiO}_{2}$ & $\begin{array}{l}\text { WCA } \\
\text { SA }\end{array}$ & $\begin{array}{c}151.5^{\circ} \\
9.0^{\circ}\end{array}$ & [129] \\
\hline Nanoparticle & Coating & $\begin{array}{c}\text { PDMS/Spray-coated } \\
\text { CNP }\end{array}$ & WCA & $167.0^{\circ}$ & [133] \\
\hline Nanoparticle & Sponge & $\mathrm{PDMS} / \mathrm{SiO}_{2} / \mathrm{WS}_{2}$ & $\begin{array}{c}\text { WCA } \\
\text { Separation } \\
\text { Efficiency }\end{array}$ & $\begin{array}{c}158.8 \pm 1.4^{\circ} \\
99.8 \%\end{array}$ & [97] \\
\hline Nanoparticle & Coating & $\begin{array}{c}\mathrm{SiO}_{2} / \mathrm{PDMS} \text { and Bees- } \\
\text { wax }\end{array}$ & $\begin{array}{l}\text { WCA } \\
\text { SA }\end{array}$ & $\begin{array}{c}154.6^{\circ} \\
5.0^{\circ}\end{array}$ & [98] \\
\hline Nanoparticle & Coating & $\mathrm{PDMS} / \mathrm{TiO}_{2}$ & $\begin{array}{c}\text { WCA } \\
\text { Properties }\end{array}$ & $\begin{array}{l}102.0^{\circ} \\
\text { Improved the } \\
\text { anticorrosion }\end{array}$ & [102] \\
\hline Nanoparticle & $\begin{array}{l}\text { Mechanical } \\
\text { Properties }\end{array}$ & $\begin{array}{l}\text { MQ resin in silica sol } \\
\text { and V-PDMS }\end{array}$ & $\begin{array}{c}\text { Young's modulus } \\
\text { TS }\end{array}$ & $\begin{array}{c}0.2 \mathrm{MPa} \\
1.9 \mathrm{MPa} \\
158.0^{\circ}\end{array}$ & [134] \\
\hline Nanoparticle & Coating & $\mathrm{PDMS} / \mathrm{TiO}_{2}$ & $\begin{array}{c}\text { WCA } \\
\text { SA } \\
\text { Separation } \\
\text { Efficiency } \\
\text { Properties }\end{array}$ & $\begin{array}{c}5.0^{\circ} \\
\text { Oil/water } \\
99.5 \% \\
\text { Improved } \\
\text { Abrasion } \\
\text { Resistant } \\
164.0^{\circ}\end{array}$ & [100] \\
\hline Particle & Coating & PDMS/PHC & $\begin{array}{c}\text { WCA } \\
\text { SA } \\
\text { Properties }\end{array}$ & $\begin{array}{c}3.7^{\circ} \\
\text { Improved } \\
\text { Mechanical } \\
\text { Durability }\end{array}$ & [122] \\
\hline Particle & Membrane & $\mathrm{PDMS} / \mathrm{SiO}_{2} / \mathrm{PVDF}$ & $\begin{array}{c}\text { WCA } \\
\text { Elongation at break }\end{array}$ & $\begin{array}{c}131.8^{\circ} \\
158.0 \%\end{array}$ & [121] \\
\hline Particles & Membrane & PDMS-silicate-1 & WCA & $135.2^{\circ}$ & {$[50]$} \\
\hline Wax & Coating & $\begin{array}{c}\text { PDMS-MCNTs-Bees- } \\
\text { wax }\end{array}$ & $\begin{array}{l}\text { WCA } \\
\text { SA }\end{array}$ & $\begin{array}{c}158.3^{\circ} \\
1.4^{\circ}\end{array}$ & [115] \\
\hline Wax & Coating & $\begin{array}{c}\text { Carnauba wax/PDMS- } \\
\text { paper }\end{array}$ & $\begin{array}{l}\text { WCA } \\
\text { SA }\end{array}$ & $\begin{array}{c}169.0^{\circ} \\
3.0^{\circ}\end{array}$ & [116] \\
\hline Wax & $\begin{array}{c}\text { Multifunctional } \\
\text { Material }\end{array}$ & PDMS/Paraffin & Transparency & $80 \%$ & [108] \\
\hline Wax & $\begin{array}{c}\text { Multifunctional } \\
\text { Material }\end{array}$ & PDMS/Paraffin & Transparency & $85.5 \%$ & [109] \\
\hline Wax & $\begin{array}{c}\text { Multifunctional } \\
\text { Material }\end{array}$ & P-PDMS & Transparency & $\sim 94.0 \%$ & [112] \\
\hline Wax & $\begin{array}{c}\text { Multifunctional } \\
\text { Material }\end{array}$ & PDMS/Paraffin & Transparency & $85.0 \%$ & [114] \\
\hline Wax & Coating & Carnauba wax/PDMS & $\begin{array}{l}\text { WCA } \\
\text { SA }\end{array}$ & $\begin{array}{r}162.0^{\circ} \\
10.0^{\circ}\end{array}$ & [117] \\
\hline Wax & Coating & PDMS/Paraffin & $\begin{array}{c}\text { WCA } \\
\text { Separation } \\
\text { Efficiency }\end{array}$ & $\begin{array}{c}156.7^{\circ} \\
\text { Diesel oil/water } \\
95 \%\end{array}$ & [110] \\
\hline Wax & $\begin{array}{l}\text { Mechanical } \\
\text { Properties }\end{array}$ & PDMS/Paraffin & $\begin{array}{c}\text { TS } \\
\text { Transparency }\end{array}$ & $\begin{array}{l}2 \mathrm{MPa} \\
\sim 99 \%\end{array}$ & [107] \\
\hline Wax & $\begin{array}{l}\text { Mechanical } \\
\text { Properties }\end{array}$ & PDMS/Beeswax & $\begin{array}{c}\text { WCA } \\
\text { TS } \\
\text { Hardness } \\
\text { Transparency }\end{array}$ & $\begin{array}{c}129.3^{\circ} \\
1.1 \mathrm{MPa} \\
28[\text { Shore A] } \\
71 \%\end{array}$ & [75] \\
\hline Wax & Mechanical & PDMS/Paraffin & WCA & $141.9^{\circ}$ & [75] \\
\hline
\end{tabular}




\begin{tabular}{|c|c|c|c|c|c|}
\hline & Properties & & TS & $2.6 \mathrm{MPa}$ & \\
\hline & & & $\begin{array}{l}\text { Haraness } \\
\text { Transparency }\end{array}$ & $\begin{array}{c}33.2[\text { snore A] } \\
72 \%\end{array}$ & \\
\hline Fiber & $\begin{array}{l}\text { Mechanical } \\
\text { Properties }\end{array}$ & $\begin{array}{c}\text { Poliacrilonitrila-graft- } \\
\text { PDMS }\end{array}$ & $\begin{array}{l}\text { Young's modulus } \\
\text { Tensile strength }\end{array}$ & $\begin{array}{c}\text { Increased } 56 \% \\
\text { Increased } 60 \% \text { non- } \\
\text { woven }\end{array}$ & [86] \\
\hline Fiber & $\begin{array}{l}\text { Mechanical } \\
\text { Properties }\end{array}$ & graphene foam/PDMS & $\begin{array}{l}\text { Young's modulus } \\
\text { Tensile strength }\end{array}$ & $\begin{array}{l}\text { Increased } 71 \% \\
\text { Increased 52\% }\end{array}$ & [87] \\
\hline Fiber & $\begin{array}{l}\text { Mechanical } \\
\text { Properties }\end{array}$ & $\begin{array}{c}\text { Silica continuous } \\
\text { /PDMS }\end{array}$ & $\begin{array}{l}\text { Maximum strain } \\
\text { Tensile Strength }\end{array}$ & $\begin{array}{c}\text { Increased } 94 \% \\
\text { Increased } 140 \%\end{array}$ & [81] \\
\hline
\end{tabular}

According to the results presented in the table, PDMS composites modify the mechanical, thermal, and surface wettability properties of PDMS. The additive-type studies by Zieh Pan et al. [127], Xiashi Ren et al. [126] and Gao Shouwei et al. [124] showed that addition composites help to increase the surface hydrophobicity of PDMS sponges and membranes, thus improving the effectiveness for filtering oil in water and extracting heavy ions. Another study by A. Syafiq et al. also modified the surface of PDMS to increase hydrophobicity and fabricate a self-cleaning glass substrate [128]. The works by Wei Qian et al. [10], Huaxin Rao et al. [19], and Long-Fei Ren et al. [15] sought to improve the mechanical properties of PDMS by adding reduced graphene oxide (rGO), liquid crystal (LC), and PMMA sheets for different applications such as biomedical in skin dressing and its direct application in the separation of wastewater. The additive-type PDMS composites presented seek not only to improve mechanical properties and increase surface hydrophobicity, but also to reduce costs, proposing efficient and simple operation and manufacturing methods.

Some other types of materials reported are polymeric nanocomposites. Amir M. Nazari et al. [132], with the objective of manufacturing thin films to be applied in microfluidic devices, reinforced PDMS with nanoclay platelets and, by increasing the nanoclay content, improved the elasticity of PDMS but decreased the shear strength. Yanbing Luo et al. [131] used tetraethoxysilane (TEOS) nanocomposites to impart hydrophobic properties to sandstone and thus preserve it. In general, nanocomposites have physical properties superior to conventional composites in terms of strength, rigidity, thermal, and oxidative stability [132].

The vast majority of studies with nanoparticles were carried out to increase the hydrophobicity of PDMS $[97,99,101,129,133]$, transforming the surfaces of coatings and sponges into super-hydrophobic surfaces, i.e., the angle of contact with water is greater than $150^{\circ}$. These are used for different applications such as self-cleaning surfaces, low infrared emissivity, and the adsorption (separation) of oil in water. However, in some studies $[82,102]$ the hydrophobicity of PDMS was maintained, changing only the roughness [82] and its applications in anti-corrosive coatings [102] and in implants [82]. In a general context, for some applications the disadvantage of composites with nanoparticles is the loss of transparency. Similarly, studies carried out with particles changed the hydrophobicity of PDMS, increasing its value. Shiquan Hang [122] used poly [hexeafluorobisphenol A-co-cyclotriphosphazene] (PHC) to create superhydrophobic coatings with an angle of contact with water of $164^{\circ}$ in order to produce a self-cleaning and anti-freezing surface with mechanical properties and durability in aggressive environments. However, this type of composite is not suitable for applications where the transparency of PDMS is required.

PDMS composites with different types of waxes mostly alter the hydrophobic, transparency, and mechanical properties. One of the characteristics so far unnoticed in previous studies and observed in wax composites with PDMS is the possibility to control the transparency with increasing temperatures. In works that use paraffin, the composite films at room temperature remain opaque; however, as the temperature increases, the composite becomes transparent, reaching 99\% transparency [43], in addition to the use of 
paraffin, which alters the hydrophobicity of PDMS, making it super-hydrophobic [110]. Another concern demonstrated with this type of composite is the use of biocompatible materials such as carnauba [116], so that the biocompatibility characteristics of PDMS are not changed, which enables the use of the composite in biomedical applications.

Finally, fiber composites with PDMS matrix reinforce the mechanical properties of PDMS Hao-Yang Mi [81] used silica fibers that increased the tensile modulus and strength by $140 \%$ and $94 \%$, respectively, with a $20 \%$ loss of transparency. We can also note that this type of composite can improve thermal properties; as in the composite with graphene foam, short carbon fibers, and PDMS, this composite improved thermal conductivity by $41 \%$, tensile strength by $52 \%$, and Young's modulus by $71 \%$ [87] when compared to pure PDMS.

\section{Conclusions}

PDMS has become a widely used material in many research fields, and its range of applications increases every year. This increase is reflected in the large number of works that have been studying and modifying this material, resulting in tailored properties for extremely specific purposes. This review provides an outlook of how PDMS composites could have their main properties improved, such as their mechanical, electrical, and optical features, opening up new avenues and applications in various fields of engineering. The next generation of PDMS composite materials should focus on improving and standardizing the manufacturing of PDMS mixed with other materials, such as waxes, and seek efficient processes that facilitate the manufacturing process at a low cost, which would allow for the replacement of conventional processes and large-scale engineering application. Additionally, PDMS can be widely explored in new emergent technologies, as in the field of transparent films for photovoltaic panels, which continues to be a future trend for sustainable and renewable energy.

Funding: This research was partially funded by the Portuguese national funds of FCT/MCTES (PIDDAC) through the base funding from the following research units: UIDB/00690/2020 (CIMO), UIDB/04077/2020 (MEtRICs) and UIDB/00532/2020 (CEFT). The authors are also grateful for the funding of ANI and CIMO through the projects POCI-01-02B7-FEDER-069844 and CMFPE3EXPL2021CIMO_01, respectively. The authors also acknowledge partial financial support from the project NORTE-01-0145-FEDER-030171 (PTDC/EMD-EMD/30171/2017) funded by the NORTE 2020 Portugal Regional Operational Programme, under the PORTUGAL 2020 Partnership Agreement, through the European Regional Development Fund (FEDER) and by Fundaçao para a Ciencia e Tecnologia (FCT).

Institutional Review Board Statement: Not applicable.

Informed Consent Statement: Not applicable.

Conflicts of Interest: The authors declare no conflict of interest.

\section{References}

1. Feldman, D. Polymer History. Des. Monomers Polym. 2008, 11, 1-15, doi:10.1163/156855508x292383.

2. Gad, S.E. Polymers, Encyclopedia of Toxicology, 3rd ed.; Elsevier: Amsterdam, The Netherlands, 2014; pp. 1045-1050.

3. Adiguzel, Z.; Sagnic, S.A.; Aroguz, A.Z. Preparation and characterization of polymers based on PDMS and PEG-DMA as potential scaffold for cell growth. Mater. Sci. Eng. C 2017, 78, 942-948, doi:10.1016/j.msec.2017.04.077.

4. Giri, R.; Naskar, K.; Nando, G.B. Effect of electron beam irradiation on dynamic mechanical, thermal and morphological properties of LLDPE and PDMS rubber blends. Radiat. Phys. Chem. 2012, 81, 1930-1942, doi:10.1016/j.radphyschem.2012.08.004.

5. Fanse, S.; Bao, Q.; Zou, Y.; Wang, Y.; Burgess, D.J. Effect of crosslinking on the physicochemical properties of polydimethylsiloxane-based levonorgestrel intrauterine systems. Int. J. Pharm. 2021, 609, 121192, doi:10.1016/j.ijpharm.2021.121192.

6. Namazi, H. Polymers in our daily life. BioImpacts 2017, 7, 73-74, doi:10.15171/bi.2017.09.

7. Damodara, S.; George, D.; Sen, A. Single step fabrication and characterization of PDMS micro lens and its use in optocapillary flow manipulation. Sens. Actuators B Chem. 2016, 227, 383-392, doi:10.1016/j.snb.2015.12.070.

8. Cruz-Félix, A.S.; Santiago-Alvarado, A.; Márquez-García, J.; González-García, J. PDMS samples characterization with variations of synthesis parameters for tunable optics applications. Heliyon 2019, 5, e03064, doi:10.1016/j.heliyon.2019.e03064. 
9. Smith, J.A.; Li, S.; Mele, E.; Goulas, A.; Engstrøm, D.; Silberschmidt, V.V. Printability and mechanical performance of biomedical PDMS-PEEK composites developed for material extrusion. J. Mech. Behav. Biomed. Mater. 2021, 115, 104291, doi:10.1016/j.jmbbm.2020.104291.

10. Qian, W.; Hu, X.; He, W.; Zhan, R.; Liu, M.; Zhou, D.; Huang, Y.; Wang, Z.; Fei, G.; Wu, J.; et al. Polydimethylsiloxane incorporated with reduced graphene oxide (rGO) sheets for wound dressing application: Preparation and characterization. Colloids Surf. B Biointerfaces 2018, 166, 61-71, doi:10.1016/j.colsurfb.2018.03.008.

11. Yamamoto, Y.; Harada, S.; Yamamoto, D.; Honda, W.; Arie, T.; Akita, S.; Takei, K. Printed multifunctional flexible device with an integrated motion sensor for health care monitoring. Sci. Adv. 2016, 2, e1601473, doi:10.1126/sciadv.1601473.

12. Arshad, M.; Zubair, M.; Rahman, S.S.; Ullah, A. Polymers for advanced applications. Polym. Sci. Nanotechnol. 2020, 325-340, doi:10.1016/b978-0-12-816806-6.00014-5.

13. Sastri, V.R. Materials Used in Medical Devices, Plastics in Medical Devices; Elsevier: Amsterdam, The Netherlands, $2010 ;$ pp. 21-32.

14. McKeen, L. The Effect of Sterilization on Plastics and Elastomers; Elsevier BV: Amsterdam, The Netherlands, $2012 ;$ pp. 319-353.

15. Ren, L.-F.; Liu, C.; Xu, Y.; Zhang, X.; Shao, J.; He, Y. High-performance electrospinning-phase inversion composite PDMS membrane for extractive membrane bioreactor: Fabrication, characterization, optimization and application. J. Membr. Sci. 2020, 597, 117624, doi:10.1016/j.memsci.2019.117624.

16. Zeng, Z.; Wei, S.; Taylor, S.E. Facile preparation of superhydrophobic melamine sponge for efficient underwater oil-water separation. Sep. Purif. Technol. 2020, 247, 116996.

17. Dalla Monta, A.; Razan, F.; Le Cam, J.B.; Chagnon, G. Using thickness-shear mode quartz resonator for characterizing the viscoelastic properties of PDMS during cross-linking, from the liquid to the solid state and at different temperatures. Sens. Actuators A Phys. 2018, 280, 107-113.

18. Montazerian, H.; Mohamed, M.; Montazeri, M.M.; Kheiri, S.; Milani, A.; Kim, K.; Hoorfar, M. Permeability and mechanical properties of gradient porous PDMS scaffolds fabricated by 3D-printed sacrificial templates designed with minimal surfaces. Acta Biomater. 2019, 96, 149-160, doi:10.1016/j.actbio.2019.06.040.

19. Rao, H.; Zhang, Z.; Liu, F. Enhanced mechanical properties and blood compatibility of PDMS/liquid crystal cross-linked membrane materials. J. Mech. Behav. Biomed. Mater. 2013, 20, 347-353, doi:10.1016/j.jmbbm.2013.01.010.

20. Souza, A.; Marques, E.; Balsa, C.; Ribeiro, J. Characterization of Shear Strain on PDMS: Numerical and Experimental Approaches. Appl. Sci. 2020, 10, 3322, doi:10.3390/app10093322.

21. Salazar-Hernández, C.; Salazar-Hernández, M.; Carrera-Cerritos, R.; Mendoza-Miranda, J.M.; Elorza-Rodríguez, E.; MirandaAviles, R.; Mocada-Sánchez, C.D. Anticorrosive properties of PDMS-Silica coatings: effect of methyl, phenyl and amino groups. Prog. Org. Coat. 2019, 136, 105220, doi:10.1016/j.porgcoat.2019.105220.

22. Eduok, U.; Faye, O.; Szpunar, J. Recent developments and applications of protective silicone coatings: A review of PDMS functional materials. Prog. Org. Coat. 2017, 111, 124-163, doi:10.1016/j.porgcoat.2017.05.012.

23. An, A.K.; Guo, J.; Lee, E.-J.; Jeong, S.; Zhao, Y.; Wang, Z.; Leiknes, T. PDMS/PVDF hybrid electrospun membrane with superhydrophobic property and drop impact dynamics for dyeing wastewater treatment using membrane distillation. J. Membr. Sci. 2017, 525, 57-67, doi:10.1016/j.memsci.2016.10.028.

24. Pinho, D.; Muñoz-Sánchez, B.; Anes, C.; Vega, E.J.; Lima, R. Flexible PDMS microparticles to mimic RBCs in blood particulate analogue fluids. Mech. Res. Commun. 2019, 100, 18-20, doi:10.1016/j.mechrescom.2019.103399.

25. Wolf, M.P.; Salieb-Beugelaar, G.B.; Hunziker, P. PDMS with designer functionalities-Properties, modifications strategies, and applications. Prog. Polym. Sci. 2018, 83, 97-134, doi:10.1016/j.progpolymsci.2018.06.001.

26. Amjadi, M.; Pichitpajongkit, A.; Lee, S.; Ryu, S.; Park, I. Highly Stretchable and Sensitive Strain Sensor Based on Silver Nanowire-Elastomer Nanocomposite. ACS Nano 2014, 8, 5154-5163, doi:10.1021/nn501204t.

27. Yun, Y.J.; Ju, J.; Lee, J.H.; Moon, S.-H.; Park, S.-J.; Kim, Y.H.; Hong, W.G.; Ha, D.H.; Jang, H.; Lee, G.H.; et al. Highly Elastic Graphene-Based Electronics Toward Electronic Skin. Adv. Funct. Mater. 2017, 27, 1701513, doi:10.1002/adfm.201701513.

28. Rodrigues, R.O.; Lima, R.; Gomes, H.T.; Silva, A.M.T. Polymer microfluidic devices: an overview of fabrication methods. U. Porto J. Eng. 2015, 1, 67-79, doi:10.24840/2183-6493_001.001_0007.

29. Heo, B.; Fiola, M.; Yang, J.H.; Koh, A. A low-cost, composite collagen-PDMS material for extended fluid retention in the skininterfaced microfluidic devices. Colloid Interface Sci. Commun. 2020, 38, 100301, doi:10.1016/j.colcom.2020.100301.

30. Maram, S.K.; Barron, B.; Leung, J.C.; Pallapa, M.; Rezai, P. Fabrication and thermoresistive behavior characterization of threedimensional silver-polydimethylsiloxane (Ag-PDMS) microbridges in a mini-channel. Sens. Actuators A Phys. 2018, 277, 43-51, doi:10.1016/j.sna.2018.04.047.

31. Akther, F.; Yakob, S.; Nguyen, N.-T.; Ta, H. Surface Modification Techniques for Endothelial Cell Seeding in PDMS Microfluidic Devices. Biosensors 2020, 10, 182, doi:10.3390/bios10110182.

32. Boas, L.V.; Faustino, V.; Lima, R.; Miranda, J.M.; Minas, G.; Fernandes, C.S.V.; Catarino, S.O. Assessment of the Deformability and Velocity of Healthy and Artificially Impaired Red Blood Cells in Narrow Polydimethylsiloxane (PDMS) Microchannels. Micromachines 2018, 9, 384, doi:10.3390/mi9080384.

33. Faustino, V.; Rodrigues, R.O.; Pinho, D.; Costa, E.; Santos-Silva, A.; Miranda, V.; Amaral, J.S.; Lima, R. A Microfluidic Deformability Assessment of Pathological Red Blood Cells Flowing in a Hyperbolic Converging Microchannel. Micromachines 2019, 10, 645, doi:10.3390/mi10100645.

34. Catarino, S.O.; Rodrigues, R.O.; Pinho, D.; Miranda, J.M.; Minas, G.; Lima, R. Blood Cells Separation and Sorting Techniques of Passive Microfluidic Devices: From Fabrication to Applications. Micromachines 2019, 10, 593, doi:10.3390/mi10090593. 
35. Bento, D.; Lopes, S.; Maia, I.; Lima, R.; Miranda, J.M. Bubbles Moving in Blood Flow in a Microchannel Network: The Effect on the Local Hematocrit. Micromachines 2020, 11, 344, doi:10.3390/mi11040344.

36. Souza, R.R.; Gonçalves, I.M.; Rodrigues, R.O.; Minas, G.; Miranda, J.M.; Moreira, A.L.N.; Lima, R.; Coutinho, G.; Pereira, J.E.; Moita, A.S. Recent advances on the thermal properties and applications of nanofluids: From nanomedicine to renewable energies. Appl. Therm. Eng. 2022, 201, 117725.

37. Maia, I.; Rocha, C.; Pontes, P.; Cardoso, V.; Miranda, J.M.; Moita, A.S.; Minas, G.; Moreira, A.L.; Lima, R. Heat Transfer and Fluid Flow Investigations in PDMS Microchannel Heat Sinks Fabricated by Means of a Low-Cost 3D Printer. In Advances in Microfluidic Technologies for Energy and Environmental Applications; IntechOpen: London, UK, 2020.

38. Souza, A.; Souza, M.; Pinho, D.; Agujetas, R.; Ferrera, C.; Lima, R.; Puga, H.; Ribeiro, J. 3D manufacturing of intracranial aneurysm biomodels for flow visualizations: Low cost fabrication processes. Mech. Res. Commun. 2020, 107, 103535, doi:10.1016/j.mechrescom.2020.103535.

39. Carvalho, V.; Maia, I.; Souza, A.; Ribeiro, J.; Costa, P.; Puga, H.; Teixeira, S.; Lima, R.A. In vitro Biomodels in Stenotic Arteries to Perform Blood Analogues Flow Visualizations and Measurements: A Review. Open Biomed. Eng. J. 2020, 14, 87-102, doi:10.2174/1874120702014010087.

40. Carvalho, V.; Gonçalves, I.; Lage, T.; Rodrigues, R.; Minas, G.; Teixeira, S.; Moita, A.; Hori, T.; Kaji, H.; Lima, R. 3D Printing Techniques and Their Applications to Organ-on-a-Chip Platforms: A Systematic Review. Sensors 2021, 21, 3304, doi:10.3390/s21093304.

41. Rodrigues, R.O.; Sousa, P.C.; Gaspar, J.; Bañobre-López, M.; Lima, R.; Minas, G. Organ-on-a-Chip: A Preclinical Microfluidic Platform for the Progress of Nanomedicine. Small 2020, 16, 2003517.

42. Sadek, S.; Rubio, M.; Lima, R.; Vega, E. Blood Particulate Analogue Fluids: A Review. Materials 2021, 14, 2451, doi:10.3390/ma14092451.

43. Carneiro, J.; Lima, R.; Campos, J.B.L.M.; Miranda, J.M. A microparticle blood analogue suspension matching blood rheology. Soft Matter 2021, 17, 3963-3974, doi:10.1039/d1sm00106j.

44. Muñoz-Sánchez, B.N.; Silva, S.F.; Pinho, D.; Vega, E.J.; Lima, R. Generation of micro-sized PDMS particles by a flow focusing technique for biomicrofluidics applications. Biomicrofluidics 2016, 10, 014122, doi:10.1063/1.4943007.

45. Anes, C.F.; Pinho, D.; Sánchez, B.N.M.; Vega, E.J.; Lima, R. Shrinkage and colour in the production of micro-sized PDMS particles for microfluidic applications. J. Micromech. Microeng. 2018, 28, 075002, doi:10.1088/1361-6439/aab7b9.

46. López, M.; Rubio, M.; Sadek, S.; Vega, E. A simple emulsification technique for the production of micro-sized flexible powder of polydimethylsiloxane (PDMS). Powder Technol. 2020, 366, 610-616, doi:10.1016/j.powtec.2020.03.022.

47. Huang, Y.; Dong, W.; Huang, T.; Wang, Y.; Xiao, L.; Su, Y.; Yin, Z. Self-similar design for stretchable wireless LC strain sensors. Sens. Actuators A Phys. 2015, 224, 36-42, doi:10.1016/j.sna.2015.01.004.

48. Fan, S.; Liu, J.; Tang, X.; Wang, W.; Xiao, Z.; Qiu, B.; Wang, Y.; Jian, S.; Qin, Y.; Wang, Y. Process operation performance of PDMS membrane pervaporation coupled with fermentation for efficient bioethanol production. Chin. J. Chem. Eng. 2019, 27, 1339-1347, doi:10.1016/j.cjche.2018.12.005.

49. Nam, Y.-H.; Lee, S.-K.; Kim, J.-H.; Park, J.-H. PDMS membrane filter with nano-slit array fabricated using three-dimensional silicon mold for the concentration of particles with bacterial size range. Microelectron. Eng. 2019, 215, 111008, doi:10.1016/j.mee.2019.111008.

50. Zhuang, X.; Chen, X.; Su, Y.; Luo, J.; Feng, S.; Zhou, H.; Wan, Y. Surface modification of silicalite-1 with alkoxysilanes to improve the performance of PDMS/silicalite-1 pervaporation membranes: Preparation, characterization and modeling. J. Membr. Sci. 2016, 499, 386-395, doi:10.1016/j.memsci.2015.10.018.

51. Hwang, J.; Kim, Y.; Yang, H.; Oh, J.H. Fabrication of hierarchically porous structured PDMS composites and their application as a flexible capacitive pressure sensor. Compos. Part B Eng. 2021, 211, 108607, doi:10.1016/j.compositesb.2021.108607.

52. Kacik, D.; Martincek, I. Toluene optical fibre sensor based on air microcavity in PDMS. Opt. Fiber Technol. 2017, 34, 70-73, doi:10.1016/j.yofte.2017.01.006.

53. Yi, D.; Huo, Z.; Geng, Y.; Li, X.; Hong, X. PDMS-coated no-core fiber interferometer with enhanced sensitivity for temperature monitoring applications. Opt. Fiber Technol. 2020, 57, 102185, doi:10.1016/j.yofte.2020.102185.

54. Hu, H.; Li, S.; Ying, C.; Zhang, R.; Li, Y.; Qian, W.; Zheng, L.; Fu, X.; Liu, Q.; Hu, S.; et al. Hydrophilic PDMS with a sandwichlike structure and no loss of mechanical properties and optical transparency. Appl. Surf. Sci. 2020, 503, 144126, doi:10.1016/j.apsusc.2019.144126.

55. Park, J.S.; Cabosky, R.; Ye, Z.; Kim, I. (Isaac) Investigating the mechanical and optical properties of thin PDMS film by flatpunched indentation. Opt. Mater. 2018, 85, 153-161, doi:10.1016/j.optmat.2018.08.051.

56. Mahian, O.; Bellos, E.; Markides, C.N.; Taylor, R.A.; Alagumalai, A.; Yang, L.; Qin, C.; Lee, B.J.; Ahmadi, G.; Safaei, M.R.; et al. Recent advances in using nanofluids in renewable energy systems and the environmental implications of their uptake. Nano Energy 2021, 86, 106069, doi:10.1016/j.nanoen.2021.106069.

57. Gao, Z.; Song, G.; Zhang, X.; Li, Q.; Yang, S.; Wang, T.; Li, Y.; Zhang, L.; Guo, L.; Fu, Y. A facile PDMS coating approach to roomtemperature gas sensors with high humidity resistance and long-term stability. Sens. Actuators B Chem. 2020, 325, 128810, doi:10.1016/j.snb.2020.128810.

58. Lee, J.H.; Kim, D.H.; Han, S.W.; Kim, B.R.; Park, E.J.; Jeong, M.-G.; Kim, J.H.; Kim, Y.D. Fabrication of superhydrophobic fibre and its application to selective oil spill removal. Chem. Eng. J. 2016, 289, 1-6, doi:10.1016/j.cej.2015.12.026. 
59. He, X.; Wang, T.; Li, Y.; Chen, J.; Li, J. Fabrication and characterization of micro-patterned PDMS composite membranes for enhanced ethanol recovery. J. Membr. Sci. 2018, 563, 447-459, doi:10.1016/j.memsci.2018.06.015.

60. Colas, A.; Curtis, J. Silicones, Handbook of Polymer Applications in Medicine and Medical Devices; Elsevier Inc.: Amsterdam, The Netherlands, 2013; pp. 131-143.

61. Anderson, D. A of SJWE S Analysis of Silicones; Lee, S., Ed.; Wiley, New York, NY, USA, 1974.

62. Ninago, M.; Satti, A.; Ressia, J.; Ciolino, A.; Valles, E.; Villar, M. Well-Defined Synthesis of Poly(dimethylsiloxane) Homopolymers. Chem. Eng. Trans. 2009, 17, 1729-1734.

63. Oulad Hammouch, S.; Beinert, G.; Zilliox, J.; Herz, J. Synthesis and characterization of monofunctional polydimethylsiloxanes with a narrow molecular weight distribution. Polymer 1995, 36, 421-426.

64. Seethapathy, S.; Gorecki, T. Applications of polydimethylsiloxane in analytical chemistry: A review. Anal. Chim. Acta 2012, 750, $48-62$.

65. Sia, S.K.; Whitesides, G.M. Microfluidic devices fabricated in poly(dimethylsiloxane) for biological studies. Electrophoresis 2003, 24, 3563-3576.

66. Tanaka, M.; Sato, K.; Kitakami, E.; Kobayashi, S.; Hoshiba, T.; Fukushima, K. Design of biocompatible and biodegradable polymers based on intermediate water concept. Polym. J. 2015, 47, 114-121, doi:10.1038/pj.2014.129.

67. Victor, A.; Apolónia, S.; Ribeiro, J.; Araújo, F.F. Portugal Study of PDMS characterization and its applications in biomedicine: A review. J. Mech. Eng. Biomech. 2019, 4, 1-9, doi:10.24243/jmeb/4.1.163.

68. Zhang, G.; Sun, Y.; Qian, B.; Gao, H.; Zuo, D. Experimental study on mechanical performance of polydimethylsiloxane (PDMS) at various temperatures. Polym. Test. 2020, 90, 106670, doi:10.1016/j.polymertesting.2020.106670.

69. Johnston, I.; McCluskey, D.; Tan, C.K.L.; Tracey, M. Mechanical characterization of bulk Sylgard 184 for microfluidics and microengineering. J. Micromech. Microeng. 2014, 24, 035017, doi:10.1088/0960-1317/24/3/035017.

70. Khanafer, K.; Duprey, A.; Schlicht, M.; Berguer, R. Effects of strain rate, mixing ratio, and stress-strain definition on the mechanical behavior of the polydimethylsiloxane (PDMS) material as related to its biological applications. Biomed. Microdevices 2008, 11, 503-508, doi:10.1007/s10544-008-9256-6.

71. Kim, J.M.; Wolf, F.; Baier, S.K. Effect of varying mixing ratio of PDMS on the consistency of the soft-contact Stribeck curve for glycerol solutions. Tribol. Int. 2015, 89, 46-53, doi:10.1016/j.triboint.2014.12.010.

72. Musil, J.; Kunc, F.; Zeman, H.; Poláková, H. Relationships between hardness, Young's modulus and elastic recovery in hard nanocomposite coatings. Surf. Coat. Technol. 2002, 154, 304-313, doi:10.1016/s0257-8972(01)01714-5.

73. Sun, W.-J.; Kothari, S.; Sun, C.C. The relationship among tensile strength, Young's modulus, and indentation hardness of pharmaceutical compacts. Powder Technol. 2018, 331, 1-6, doi:10.1016/j.powtec.2018.02.051.

74. Lan, H.; Venkatesh, T. On the relationships between hardness and the elastic and plastic properties of isotropic power-law hardening materials. Philos. Mag. 2013, 94, 35-55, doi:10.1080/14786435.2013.839889.

75. Sales, F.; Souza, A.; Ariati, R.; Noronha, V.; Giovanetti, E.; Lima, R.; Ribeiro, J. Composite Material of PDMS with Interchangeable Transmittance: Study of Optical, Mechanical Properties and Wettability. J. Compos. Sci. 2021, 5, 110, doi:10.3390/jcs5040110.

76. Heinrich, G.; Klüppel, M.; Vilgis, T.A. Reinforcement of elastomers. Curr. Opin. Solid State Mater. Sci. $2002,6,195-203$.

77. Millereau, P.; Ducrot, E.; Clough, J.M.; Wiseman, M.E.; Brown, H.R.; Sijbesma, R.P.; Creton, C. Mechanics of elastomeric molecular composites. Proc. Natl. Acad. Sci. USA 2018, 115, 9110-9115, doi:10.1073/pnas.1807750115.

78. Donnet, J.B. Carbon Black: Science and Technology, 2nd ed.; CRC Press: Boca Raton, FL, USA, 2018.

79. Bokobza, L. The Reinforcement of Elastomeric Networks by Fillers. Macromol. Mater. Eng. 2004, 289, 607-621, doi:10.1002/mame.200400034.

80. Bokobza, L. Elastomeric composites. I. Silicone composites. J. Appl. Polym. Sci. 2004, 93, 2095-2104.

81. Mi, H.-Y.; Jing, X.; Huang, H.-X.; Turng, L.-S. Novel polydimethylsiloxane (PDMS) composites reinforced with three-dimensional continuous silica fibers. Mater. Lett. 2018, 210, 173-176, doi:10.1016/j.matlet.2017.09.018.

82. Tran, P.A.; Fox, K.; Tran, N. Novel hierarchical tantalum oxide-PDMS hybrid coating for medical implants: One pot synthesis, characterization and modulation of fibroblast proliferation. J. Colloid Interface Sci. 2017, 485, 106-115, doi:10.1016/j.jcis.2016.06.048.

83. Panou, A.I.; Papadokostaki, K.G.; Tarantili, P.A.; Sanopoulou, M. Effect of hydrophilic inclusions on PDMS crosslinking reaction and its interrelation with mechanical and water sorption properties of cured films. Eur. Polym. J. 2013, 49, 1803-1810, doi:10.1016/j.eurpolymj.2013.04.004.

84. Peel, L.D.; Jensen, D.W. The Response of Fiber-Reinforced Elastomers under Simple Tension. J. Compos. Mater. $2001,35,96-137$.

85. Sedláček, R.; Suchy, T.; Sochor, M.; Balik, K.; Sucharda, Z.; Šepitka, J. Effect of Sterilization Processes on the Fiber/Matrix Interphase Properties of CF/PDMS Composite to be Used in Orthopaedics. Key Eng. Mater. 2013, 586, 234-236, doi:10.4028/www.scientific.net/kem.586.234.

86. Bayley, G.; Hedenqvist, M.; Mallon, P. Large strain and toughness enhancement of poly(dimethyl siloxane) composite films filled with electrospun polyacrylonitrile-graft-poly(dimethyl siloxane) fibres and multi-walled carbon nanotubes. Polymer 2011, 52, 4061-4072, doi:10.1016/j.polymer.2011.06.011.

87. Zhao, Y.-H.; Zhang, Y.-F.; Bai, S.-L.; Yuan, X.-W. Carbon fibre/graphene foam/polymer composites with enhanced mechanical and thermal properties. Compos. Part B Eng. 2016, 94, 102-108, doi:10.1016/j.compositesb.2016.03.056. 
88. Gao, X.; Huang, Y.; Liu, Y.; Kormakov, S.; Zheng, X.; Wu, D.; Wu, D. Improved electrical conductivity of PDMS/SCF composite sheets with bolting cloth prepared by a spatial confining forced network assembly method. RSC Adv. 2017, 7, 14761-14768, doi:10.1039/C7RA02061A.

89. Zhang, F.; Wu, S.; Peng, S.; Wang, C.H. The effect of dual-scale carbon fibre network on sensitivity and stretchability of wearable sensors. Compos. Sci. Technol. 2018, 165, 131-139, doi:10.1016/j.compscitech.2018.06.019.

90. Stuber, V.L.; Deutz, D.; Bennett, J.; Cannell, D.; De Leeuw, D.M.; Van Der Zwaag, S.; Groen, P. Flexible Lead-Free Piezoelectric Composite Materials for Energy Harvesting Applications. Energy Technol. 2019, 7, 177-185, doi:10.1002/ente.201800419.

91. Yan, J.; Jeong, Y.G. High Performance Flexible Piezoelectric Nanogenerators based on BaTiO3 Nanofibers in Different Alignment Modes. ACS Appl. Mater. Interfaces 2016, 8, 15700-15709, doi:10.1021/acsami.6b02177.

92. Gao, X.; Huang, Y.; He, X.; Fan, X.; Liu, Y.; Xu, H.; Wu, D.; Wan, C. Mechanically Enhanced Electrical Conductivity of Polydimethylsiloxane-Based Composites by a Hot Embossing Process. Polymers 2019, 11, 56, doi:10.3390/polym11010056.

93. Shah, S.; Shiblee, N.I.; Mir, S.H.; Nagahara, L.A.; Thundat, T.; Sekhar, P.K.; Kawakami, M.; Furukawa, H.; Khosla, A. Hybrid micromolding of silver micro fiber doped electrically conductive elastomeric composite polymer for flexible sensors and electronic devices. Microsyst. Technol. 2017, 24, 4159-4164, doi:10.1007/s00542-017-3694-0.

94. Oh, D.-W.; Park, J.Y. Simulation of Fiber Alignment during the Injection Molding Process by Using Short Carbon Fiber and Pdms Mixture; Department of Mechanical Engineering, Chosun University; International Committee on Composite Materials: Gwangju, Korea, 2017.

95. Suchý, T.; Balík, K.; Sucharda, Z.; Sochor, M.; Lapčíková, M.; Sedlacek, R. Optimizing and evaluating the biocompatibility of fiber composites with calcium phosphate additives. Wien. Med. Wochenschr. 2011, 161, 493-502, doi:10.1007/s10354-011-0913-7.

96. Chang, R.; Chen, Z.; Yu, C.; Song, J. An Experimental Study on Stretchy and Tough PDMS/Fabric Composites. J. Appl. Mech. 2019, 86, 011012, doi:10.1115/1.4041679.

97. Zhai, G.; Qi, L.; He, W.; Dai, J.; Xu, Y.; Zheng, Y.; Huang, J.; Sun, D. Durable super-hydrophobic PDMS@SiOz@WS2 sponge for efficient oil/water separation in complex marine environment. Environ. Pollut. 2021, 269, 116118.

98. Pakzad, H.; Liravi, M.; Moosavi, A.; Nouri-Borujerdi, A.; Najafkhani, H. Fabrication of durable superhydrophobic surfaces using PDMS and beeswax for drag reduction of internal turbulent flow. Appl. Surf. Sci. 2020, 513, 145754, doi:10.1016/j.apsusc. 2020.145754 .

99. Ouyang, G.M.; Wang, K.Y.; Chen, X.Y. Enhanced electro-mechanical performance of $\mathrm{TiO}_{2}$ nano-particle modified polydimethylsiloxane (PDMS) as electroactive polymers. In Proceedings of the 16th International Solid-State Sensors, Actuators and Microsystems Conference, Beijing, China, 5-9 June 2011; pp. 614-617.

100. Bolvardi, B.; Seyfi, J.; Hejazi, I.; Otadi, M.; Khonakdar, H.A.; Davachi, S.M. Towards an efficient and durable superhydrophobic mesh coated by PDMS/TiO2 nanocomposites for oil/water separation. Appl. Surf. Sci. 2019, 492, 862-870, doi:10.1016/j.apsusc.2019.06.268.

101. Hickman, R.; Walker, E.; Chowdhury, S. TiOz-PDMS composite sponge for adsorption and solar mediated photodegradation of dye pollutants. J. Water Process. Eng. 2018, 24, 74-82, doi:10.1016/j.jwpe.2018.05.015.

102. Cui, X.; Zhu, G.; Pan, Y.; Shao, Q.; Zhao, C.; Dong, M.; Zhang, Y.; Guo, Z. Polydimethylsiloxane-titania nanocomposite coating: Fabrication and corrosion resistance. Polymer 2018, 138, 203-210, doi:10.1016/j.polymer.2018.01.063.

103. Liu, H.-K.; Yang, R.-B.; Shen, C.-Y. Effect of iron particle additions on performance of a novel electromagnetic PDMS micropump. J. Chin. Soc. Mech. Eng. Trans. Chin. Inst. Eng. Ser. C/Chung-Kuo Chi Hsueh K Ch'eng Hsuebo Pao 2012, 33, 435-445.

104. Damodara, S.; Sen, A. Magnetic field assisted droplet manipulation on a soot-wax coated superhydrophobic surface of a PDMSiron particle composite substrate. Sens. Actuators B Chem. 2017, 239, 816-823, doi:10.1016/j.snb.2016.08.086.

105. Suna, A.; Gulle, M.; Erten, A. Comparison of Magnetic Particle Incorporated PDMS Membrane Actuators. In Proceedings of the 2019 11th International Conference on Electrical and Electronics Engineering (ELECO), Bursa, Turkey, 28-30 November 2019; pp. $475-478$.

106. Si, J.; Cui, Z.; Xie, P.; Song, L.; Wang, Q.; Liu, Q.; Liu, C. Characterization of 3D elastic porous polydimethylsiloxane (PDMS) cell scaffolds fabricated by VARTM and particle leaching. J. Appl. Polym. Sci. 2016, 133, doi:10.1002/app.42909.

107. Shi, Y.; Hu, M.; Xing, Y.; Li, Y. Temperature-dependent thermal and mechanical properties of flexible functional PDMS/paraffin composites. Mater. Des. 2020, 185, 108219, doi:10.1016/j.matdes.2019.108219.

108. Owuor, P.S.; Chaudhary, V.; Woellner, C.F.; Sharma, V.; Ramanujan, R.; Stender, A.S.; Soto, M.; Ozden, S.; Barrera, E.V.; Vajtai, R.; et al. High stiffness polymer composite with tunable transparency. Mater. Today 2018, 21, 475-482, doi:10.1016/j.mattod.2017.12.004.

109. Apostoleris, H.N.; Chiesa, M.; Stefancich, M. Improved transparency switching in paraffin-PDMS composites. J. Mater. Chem. C 2015, 3, 1371-1377, doi:10.1039/C4TC02546F.

110. Zhao, Y.; Liu, E.; Fan, J.; Chen, B.; Hu, X.; He, Y.; He, C. Superhydrophobic PDMS/wax coated polyester textiles with self-healing ability via inlaying method. Prog. Org. Coat. 2019, 132, 100-107, doi:10.1016/j.porgcoat.2019.03.043.

111. Paul, U.C.; Fragouli, D.; Bayer, I.S.; Athanassiou, A. Functionalized Cellulose Networks for Efficient Oil Removal from OilWater Emulsions. Polymers 2016, 8, 52, doi:10.3390/polym8020052.

112. Park, J.Y.; Song, H.; Kim, T.; Suk, J.W.; Kang, T.J.; Jung, D.; Kim, Y.H. PDMS-paraffin/graphene laminated films with electrothermally switchable haze. Carbon 2016, 96, 805-811, doi:10.1016/j.carbon.2015.10.014.

113. Weng, M.; Chen, L.; Zhou, P.; Li, J.; Huang, Z.; Zhang, W. Low-voltage-driven, flexible and durable paraffin-polydimethylsiloxane-based composite film with switchable transparency. Chem. Eng. J. 2016, 295, 295-300, doi:10.1016/j.cej.2016.03.052. 
114. Zhang, J.; Pu, G.; Dubay, M.R.; Zhao, Y.; Severtson, S.J. Repositionable pressure-sensitive adhesive possessing thermal-stimuli switchable transparency. J. Mater. Chem. C 2013, 1, 1080-1086, doi:10.1039/c2tc00471b.

115. Weng, D.; Xu, F.; Li, X.; Li, Y.; Sun, J. Bioinspired photothermal conversion coatings with self-healing superhydrophobicity for efficient solar steam generation. J. Mater. Chem. A 2018, 6, 24441-24451, doi:10.1039/c8ta08706g.

116. Celik, N.; Sahin, F.; Ruzi, M.; Yay, M.; Unal, E.; Onses, M.S. Blood repellent superhydrophobic surfaces constructed from nanoparticle-free and biocompatible materials. Colloids Surf. B Biointerfaces 2021, 205, 111864, doi:10.1016/j.colsurfb.2021.111864.

117. Torun, I.; Ruzi, M.; Er, F.; Onses, M.S. Superhydrophobic coatings made from biocompatible polydimethylsiloxane and natural wax. Prog. Org. Coat. 2019, 136, 105279, doi:10.1016/j.porgcoat.2019.105279.

118. Liu, B.; Koh, D.; Wang, A.; Schneider, P.; Oh, K.W. Hermetic encapsulation of negative-pressure-driven PDMS microfluidic devices using paraffin wax and glass. Microsyst. Technol. 2017, 24, 2035-2043, doi:10.1007/s00542-017-3600-9.

119. Adrees, M.; Iqbal, S.S.; Ahmad, A.; Jamshaid, F.; Haider, B.; Khan, M.H.; Khan, R.; Butt, M.T.Z.; Bahadar, A. Characterization of novel polydimethylsiloxane (PDMS) and copolymer polyvinyl chloride-co-vinyl acetate (PVCA) enhanced polymer blend membranes for $\mathrm{CO}_{2}$ separation. Polym. Test. 2019, 80, 106163, doi:10.1016/j.polymertesting.2019.106163.

120. Yun, C.M.; Akiyama, E.; Yamanobe, T.; Uehara, H.; Nagase, Y. Characterizations of PDMS-graft copolyimide membrane and the permselectivity of gases and aqueous organic mixtures. Polymer 2016, 103, 214-223, doi:10.1016/j.polymer.2016.09.044.

121. Li, D.; Yao, J.; Sun, H.; Liu, B.; Li, D.; van Agtmaal, S.; Feng, C. Preparation and characterization of SiO $2 / \mathrm{PDMS}_{\mathrm{PVDF}}$ composite membrane for phenols recovery from coal gasification wastewater in pervaporation. Chem. Eng. Res. Des. 2018, 132, 424-435.

122. Hong, S.; Wang, R.; Huang, X.; Liu, H. Facile one-step fabrication of PHC/PDMS anti-icing coatings with mechanical properties and good durability. Prog. Org. Coat. 2019, 135, 263-269, doi:10.1016/j.porgcoat.2019.06.016.

123. Riehle, N.; Thude, S.; Götz, T.; Kandelbauer, A.; Thanos, S.; Tovar, G.E.; Lorenz, G. Influence of PDMS molecular weight on transparency and mechanical properties of soft polysiloxane-urea-elastomers for intraocular lens application. Eur. Polym. J. 2018, 101, 190-201, doi:10.1016/j.eurpolymj.2018.02.029.

124. Gao, S.; Dong, X.; Huang, J.; Li, S.; Li, Y.; Chen, Z.; Lai, Y. Rational construction of highly transparent superhydrophobic coatings based on a non-particle, fluorine-free and water-rich system for versatile oil-water separation. Chem. Eng. J. 2018, 333, 621-629, doi:10.1016/j.cej.2017.10.006.

125. Al-Handarish, Y.; Omisore, O.M.; Duan, W.; Chen, J.; Zebang, L.; Akinyemi, T.; Du, W.; Li, H.; Wang, L. Facile Fabrication of 3D Porous Sponges Coated with Synergistic Carbon Black/Multiwalled Carbon Nanotubes for Tactile Sensing Applications. Nanomaterials 2020, 10, 1941, doi:10.3390/nano10101941.

126. Ren, X.; Jia, Y.; Lu, X.; Shi, T.; Ma, S. Preparation and characterization of PDMS-D2EHPA extraction gel membrane for metal ions extraction and stability enhancement. J. Membr. Sci. 2018, 559, 159-169, doi:10.1016/j.memsci.2018.04.033.

127. Pan, Z.; Guan, Y.; Liu, Y.; Cheng, F. Facile fabrication of hydrophobic and underwater superoleophilic elastic and mechanical robust graphene/PDMS sponge for oil/water separation. Sep. Purif. Technol. 2021, 261, 118273, doi:10.1016/j.seppur.2020.118273.

128. Syafiq, A.; Vengadaesvaran, B.; Rahim, N.A.; Pandey, A.; Bushroa, A.; Ramesh, K.; Ramesh, S. Transparent self-cleaning coating of modified polydimethylsiloxane (PDMS) for real outdoor application. Prog. Org. Coat. 2019, 131, 232-239, doi:10.1016/j.porgcoat.2019.02.020.

129. Zhang, W.; Jiang, S.; Lv, D. Fabrication and characterization of a PDMS modified polyurethane/Al composite coating with superhydrophobicity and low infrared emissivity. Prog. Org. Coat. 2020, 143, 105622, doi:10.1016/j.porgcoat.2020.105622.

130. Riehle, N.; Götz, T.; Kandelbauer, A.; Tovar, G.E.; Lorenz, G. Data on the synthesis and mechanical characterization of polysiloxane-based urea-elastomers prepared from amino-terminated polydimethylsiloxanes and polydimethyl-methyl-phenyl-siloxane-copolymers. Data Brief 2018, 18, 1784-1794, doi:10.1016/j.dib.2018.04.083.

131. Luo, Y.; Xiao, L.; Zhang, X. Characterization of TEOS/PDMS/HA nanocomposites for application as consolidant/hydrophobic products on sandstones. J. Cult. Herit. 2015, 16, 470-478, doi:10.1016/j.culher.2014.08.002.

132. Nazari, A.M.; Miri, A.K.; Shinozaki, D.M. Mechanical characterization of nanoclay-filled PDMS thin films. Polym. Test. 2016, 52, 85-88, doi:10.1016/j.polymertesting.2016.04.006.

133. Geraldi, N.R.; Dodd, L.; Xu, B.B.; Wood, D.; Wells, G.G.; McHale, G.; I Newton, M. Bioinspired nanoparticle spray-coating for superhydrophobic flexible materials with oil/water separation capabilities. Bioinspiration Biomimetics 2017, 13, 024001, doi:10.1088/1748-3190/aaa1c1.

134. Chen, D.; Chen, F.; Hu, X.; Zhang, H.; Yin, X.; Zhou, Y. Thermal stability, mechanical and optical properties of novel addition cured PDMS composites with nano-silica sol and MQ silicone resin. Compos. Sci. Technol. 2015, 117, 307-314, doi:10.1016/j.compscitech.2015.07.003. 